\title{
ÓRDENES MENDICANTES Y ESTRUCTURAS FEUDALES DE PODER EN CASTILLA LA VIEJA (SIGLOS XIII y XIV) *
}

\author{
IGNACIO ÁLVAREZ BORGE \\ Universidad de La Rioja
}

\section{RESUMEN}

El objetivo del presente artículo es analizar y comparar la estructura de los dominios de tres casas conventuales de Castilla la Vieja en los siglos XIII y XIV. Los tres ejemplos elegidos permiten obtener una perspectiva cronológica amplia y mostrar cómo evolucionaron los mecanismos de adaptación de los mendicantes a las estructuras feudales. En segundo lugar, es posible comparar su papel como miembros de la clase señorial con el de otros señores feudales, especialmente con otras instituciones eclesiásticas de fundación anterior.

\begin{abstract}
The aim of this paper is to analyse and compare the structure of rural properties of three houses of mendicants in Castile during the thirteenth and fourteenth centuries. Analysing these three case studies we can gain a wide chronological view to show how the mendicants evolved to adapt to the feudal structures. We can also compare their role as members of the dominant class with that of other feudal lords, specially with other ecclesiastical institutions of previous foundation.
\end{abstract}

El objetivo del presente artículo es analizar y comparar la estructura de los dominios de tres casas conventuales instaladas en Castilla la Vieja en los siglos XIII y xIv. Se trata de los conventos de la Trinidad de Burgos,

* Este artículo ha sido parcialmente realizado con el apoyo de una Ayuda a la Investigación de la Universidad de la Rioja.

Revista de Historia Económica

Ano XIII, Otonis-Imiemo 1999, N." 3 . 
Santo Domingo de Caleruega y Santa Clara de Astudillo. Los tres conventos fueron fundados, respectivamente, a principios del siglo xIII (la Trinidad), en 1266 (Santo Domingo) y a mediados del siglo xIv (Santa Clara). En ese período se fundaron otros muchos conventos de mendicantes en la zona. No pretendo que los tres elegidos sean especialmente representativos del resto, pero para ellos se ha conservado documentación histórica relativamente abundante que, además, ha sido editada y es, por tanto, fácilmente accesible. El estudio pretende, entre otras cosas, llamar la atención sobre el interés del análisis de los dominios de las nuevas órdenes durante los siglos XIII y XIV, no sólo de forma aislada, como suele hacerse más frecuentemente, sino insertándolos en el conjunto de las estructuras de poder.

Las sucesivas adaptaciones, reformas, desarrolladas en el seno de la Iglesia para mantener su hegemonía religiosa son bien conocidas, y entre ellas, la que dio lugar a la expansión de los mendicantes desde principios del siglo XIII ha dado lugar a una abundante bibliografía ${ }^{1}$. No me referiré explícitamente a los aspectos religiosos, aunque obviamente haré referencias a ellos, sino que mi interés se centra en las bases materiales de su expansión religiosa e ideológica. Los tres ejemplos seleccionados corresponden a tres órdenes distintas, trinitarios, dominicos y clarisas. No pretendo incidir en las diferencias derivadas de las características de cada orden. Los tres ejemplos permiten considerar un período de tiempo bastante largo, de unos 150 años - desde principios del siglo XIII hasta mediados del siglo XIV-, en el que es posible obtener una perspectiva evolutiva.

El estudio de los dominios de estos tres conventos permite señalar ciertas características que desarrollaré en el último apartado de este artículo. Características que deben entenderse como puntos de partida para futuros análisis de otros dominios conventuales. Hay que tener en cuenta que en Castilla la Vieja las nuevas instituciones extendieron sus dominios en zonas donde la presión señorial era ya muy fuerte ${ }^{2}$. El resultado será que las nuevas órdenes no se caracterizarán por ser señores, en el sentido de que no adquirirán derechos de señorío sobre villas o aldeas, o no lo harán

${ }^{1}$ Entre los trabajos recientes puede verse Linage Conde (1983), Peña Pérez (1993) y García Turza (1996). Estos trabajos mencionan los estudios anteriores más importantes, pero Sáenz de Haro (1996) ofrece una recopilación bibliográfica muy completa. Un planteamiento parecido al que orienta este trabajo, analizando los dominios de varios conventos de dominicos, clarisas y agustinos de la ciudad de Salamanca, con algunas características similares y otras diferentes a los que analizo aquí, puede verse en Martín Martín (1997).

2 Para una visión general puede verse Estepa Diez (1994) y Álvarez Borge (1996). 
de forma importante por comparación con las instituciones eclesiásticas de fundación anterior; pero algunos conventos serán poderosos propietarios feudales con dominios considerables. Además, los mendicantes mostraron una capacidad muy temprana de absorción de los nuevos mecanismos de poder que generaba el desarrollo del feudalismo: recursos procedentes de las oligarquías urbanas de comerciantes, como es el caso del convento de la Trinidad, y significativamente recursos procedentes del desarrollo de la fiscalidad regia, como los conventos de Caleruega y Astudillo. Desde fechas muy tempranas, algunos conventos obtendrán buena parte de sus ingresos como rentistas de la monarquía. Su estudio se convierte, por tanto, en un buen precedente para conocer el desarrollo de la renta feudal centralizada en Castilla.

\section{EL DOMINIO DEL CONVENTO DE LA TRINIDAD DE BURGOS}

Una de las primeras casas en Castilla de la orden de la Santísima Trinidad se levantó en Burgos en los primeros años del siglo xiIr. La orden tenía, como característica específica, la dedicación a la redención de cautivos cristianos en manos de los musulmanes. Durante los siglos XIII y XIV el convento fue formando un dominio rural que llegó a tener una extensión considerable. Hasta ahora el dominio de la Trinidad de Burgos no ha sido analizado con detalle, pero se dispone de una interesantísima documentación públicada por L. García Aragón ${ }^{3}$.

El primer documento conservado referido a este convento es de 1207; en él Alfonso VIII le confirmaba las donaciones que le hicieron domina Catalana y Donato Guillermo ${ }^{4}$. No se conocen los bienes que entregó el segundo; probablemente era uno de los francos asentados en la ciudad y debía tratarse de bienes urbanos ${ }^{5}$. En cuanto a doña Catalana -o Catalina- en algún otro documento se la califica de nobilis mulier y, en efecto,

${ }^{3}$ García Aragón (1985) (en adelante citaré Trinidad). La autora publica 194 documentos, uno del siglo XII (la aprobación de la regla de la orden por Inocencio III en 1198), 34 del siglo XII y 159 del siglo XIV. El artículo de Ávila y Díaz de Ubierna (1961 y 1962) es el único trabajo específico que conozco sobre este convento, pero no tiene ninguna utilidad. Sobre la orden de la Trinidad en general véase Ginarte González (1979) y García Villoslada (dir.) (1982), vol. II-2, pp. 117-118 y 125-130.

+ Trinidad, doc. 5 .

' Únicamente dice que se trata de la «bereditatem quae fuit Petro Negri, quam emit Donatus Guillermi de Guillermo Petri et dedit vobiss. 
por el volumen de los bienes donados hay que pensar que se trataba de un miembro de la alta nobleza. Según la confirmación regia, Catalana entregó al convento heredades en Huérmeces, Palacios de Benaver, Monasterio, Ruyales y otras villas de las zonas de Burgos y Lara que no se especifican ${ }^{6}$. Además de ello el convento recibió otros bienes en Somuñó en $1207^{7}$, en Burgos entre ese año y $1210^{8}$ y en varias villas más antes de $1209^{9}$. Estas adquisiciones suponen el inicio del proceso de formación del dominio. En las páginas siguientes intentaré indicar brevemente las características generales de su evolución en los siglos XIII y XIV, si bien sólo pretendo una primera aproximación a su estudio que merece una monografía detallada.

A finales del siglo XIV el convento de la Trinidad disponía de propiedades extendidas por más de 50 lugares diferentes, aunque la cantidad y el tipo de bienes que tenía en unos y otros lugares eran muy diversos. He intentado resumir el proceso de formación del dominio en el Cuadro $1^{10}$.

" Se indica que dona Catalana hizo su donación en presencia del rey estando en Atienza, lugar donde se expidió también la confirmación regia. La calificación de nobilis mulier procede de dos bulas de 1209 y 1219 que confirmaban las heredades del convento; Trinidad, docs. 8 y 13. A. Linage Conde y A. Oliver consideran que este personaje era Catalina de Moncada, atribuyéndole también la entrega de otros bienes que mencionamos a continuación; véase Garcia Villoslada (dir.) (1982), vol. II-2, p. 128. Mi hipótesis es que era la esposa de don Armengol, hijo de María de Almenara; con él se la menciona en un documento de 1200 sobre Palazuelos de la Sierra; véase Menéndez Pidal (1966), doc. 155.

- Trinidad, doc. 2.

* Trinidad, doc. 6, especificándose en una confirmación papal de 1210 que se trata del «locum qui dicitur Sancti Lazari, possessiones in Castro quod dicitur Duas Germanas, solarem et possessiones in Villascusa et solarem ultra ponten Sancte Marie de Burgis, cum omnibus pertinentiis eorum»; Trinidad, doc. 9. Dudo sobre a qué lugar se refiere el Villaescusa que se menciona aqui, aunque probablemente estaba en La Bureba, y no creo que Castro se refiera a Castrojeriz.

"En las bulas de 1209 y 1219 se mencionan otras heredades en algunos lugares que no hemos podido identificar; se trata de «Tunilla», «Rubios de Broa», «Gal» 0 «Gallis», "Gosmedos», «Inter Ecclesias» y «Santi Emeterii», además de Villimar, Huérmeces, Quintanarrio, San Vicente de Buezo, Quintanilla Moricisla y Bárcena; los documentos no expresan claramente que se trate de bienes procedentes de dona Catalana; Trinidad, docs. 8 y 13.

11" Ofrezco el cuadro que puede expresar la formación del dominio entre su fundación y 1400 con la reserva de que la documentación conservada puede presentar importantes lagunas. Se conservan muchos documentos referidos a particulares entre el bloque de documentación del convento; se trata con toda probabilidad de operaciones previas sobre heredades que después pasaron a sus manos, aunque en la mayoría de los casos no se ha conservado el documento de la adquisición por el convento. No he registrado esas heredades entre los datos que ofrezco, que por ello sólo tienen un valor aproximativo. 


\section{CUADRO 1}

Evolución del dominio del convento de la Trinidad de Burgos entre su fundación y 1400

\begin{tabular}{|c|c|c|c|c|}
\hline Periodo & Donaciones & Compras & Cambios & Ventas \\
\hline 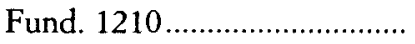 & 4 & & & \\
\hline 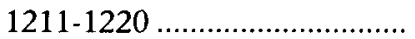 & 1 & 1 & & \\
\hline 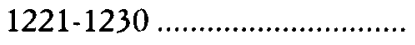 & & 1 & & \\
\hline 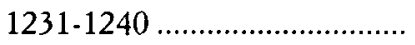 & 1 & & & \\
\hline $1241-1250 \ldots \ldots \ldots \ldots \ldots \ldots \ldots \ldots \ldots \ldots \ldots \ldots \ldots \ldots \ldots$ & 1 & 1 & & \\
\hline 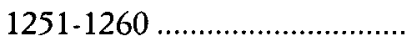 & & 1 & & \\
\hline 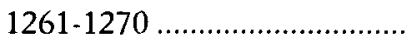 & 1 & & & \\
\hline 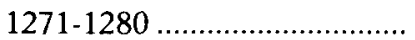 & & & 1 & \\
\hline 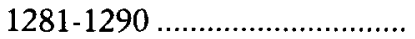 & 1 & & & \\
\hline 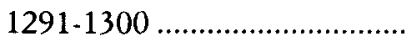 & 2 & & & \\
\hline 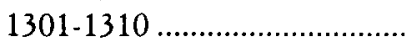 & $2 *$ & & & \\
\hline 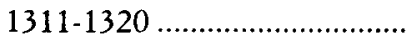 & 1 & & & \\
\hline 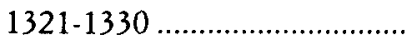 & 1 & & & \\
\hline 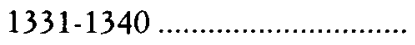 & 2 & & 1 & \\
\hline 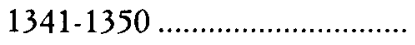 & $1 * *$ & & & \\
\hline 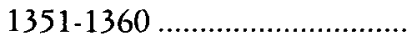 & 4 & & & \\
\hline 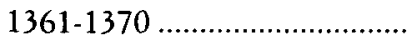 & 1 & & 1 & \\
\hline 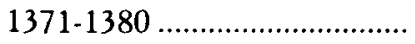 & 3 & 1 & 1 & \\
\hline 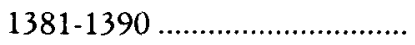 & 5 & & & 1 \\
\hline 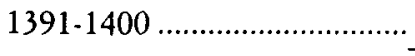 & 11 & & & \\
\hline TOTAL $\ldots . . . . . . . . . . . . . . . . . . . .$. & 42 & 5 & 4 & 1 \\
\hline
\end{tabular}

* Se conservan dos noticias, una fechada en 1304 y otra en 1342, de donaciones de Sancha Martínez que pienso que corresponden a una misma operación y que incluyo aquí; Trinidad, docs. 44 y 73 .

** Dos noticias fechadas en 1347 y 1367 dan cuenta de donaciones de Juan Rodríguez de Rojas en la misma villa, Quintanilla en La Bureba, pienso que también corresponden a una sola operación que queda incluida en este tramo; Trinidad, docs. 88 y 103.

El elemento clave en la formación del dominio de la Trinidad fueron las donaciones, de las cuales la documentación conservada registra 42 operaciones entre la fundación y 1400. Podrían señalarse, a grandes rasgos, tres momentos en la evolución del ritmo de las donaciones. El primer momento, entre 1207 y 1211, correspondería a la dotación inicial en la que fue importante el apoyo de algunos personajes concretos, como doña

He elaborado los datos a partir de la documentación publicada en Trinidad. 
Catalana. Desde entonces, durante el resto del siglo xIn, el ritmo de adquisición de propiedades mediante donaciones no fue muy intenso. Ese ritmo se intensifica claramente a finales del siglo XIII y durante el siglo XIV. Si durante el siglo XIII la Trinidad recibió 11 donaciones, durante el siglo XIV obtuvo 31. Las donaciones se hicieron más frecuentes en las últimas décadas del trescientos; así recibió 19 donaciones entre 1371 y 1400, 11 de ellas entre 1391 y 1400 . Frente a 42 donaciones, el convento de la Trinidad realizó sólo cinco operaciones de compra de bienes, todas, excepto una, en el siglo XIII en las primeras décadas tras la fundación. Era un momento en que el convento, como hemos visto, disponía ya de un pequeño dominio tras la dotación inicial, pero recibía todavía pocas donaciones. También se han conservado pocas noticias de cambios, sólo cuatro. Todo parece indicar que esos cambios pueden interpretarse en un sentido similar a muchas otras operaciones de cambio realizadas por otros monasterios y conventos. Una vez que el dominio ya tenía sus perfiles más o menos definidos era oportuno realizar ciertos reajustes para acomodar mejor la voluntad de los donantes con los intereses económicos del convento. La única venta que ha quedado registrada en la documentación conservada parece tener un sentido similar.

Las propiedades del convento se extendían por diversas zonas, sobre todo en lugares al norte y noreste de la ciudad de Burgos ${ }^{11}$. Se han con-

${ }^{11}$ Ofrezco a continuación la relación de las villas donde constan propiedades y derechos del convento de la Trinidad entre 1207 y 1400 a partir de la documentación conservada. Ello no significa que fueran todas las que se integraron en el dominio, que quizá era más amplio. Pongo entre paréntesis las fechas en que se documenta la presencia del convento, sin ofrecer otra referencia que puede encontrarse fácilmente en Trinidad. En la zona de Muñó: Palazuelos (1234, 1304 y 1342), Pampliega (1241, 1304 y 1342), Frandovínez (1271), Ciadoncha (1373) y Hornillos del Camino (1309). En el valle del Urbel: Huérmeces (1207, 1209 y 1219), Las Celadas (1250 y 1282), Pedrosa de Río Urbel (1262), Los Tremellos (1262) y Palacios de Benaver (1207). En la merindad de Silos: Cabañes de Esgueva (1391) y Oquillas (1391). En la zona de Ubierna: Quintanarrío (1209, 1211, 1219, 1251, 1292, 1353 y 1390), Quintanilla Morocisla (1209 y 1219), Mata (1211, 1251, 1292, 1372, 1390 y 1400), Villanueva de los Asnos (1271), Celadilla del Rebollar (1271), Rioseras (1331), Gredilla la Polera (1332, 1372 y 1400), Ubierna (1372), Sotopalacios (1400) y Celada de la Torre (1400). En villas próximas a Burgos (a menos de 10 kilómetros aproximadamente): Villímar (1209, 1219 y 1331), Villagonzalo Pedernales (1345 y 1346), Quintanilla de los Frailes (1400), Bascones (1400), San Medel (1400) y Castrillo de la Vega (1400). En La Bureba: Rubiales (1207), Bárcena (1209 y 1219), Buezo (1200, 1211 y 1219), Rojas (1211, 1223 y 1271), Salas (1271), Carcedo de Yuso (1271 y 1299), Carcedo de Suso (1271), Vedecilla (1271, 1319, 1321, 1357 y 1359), Quintanilla (1347 y 1367), Hermosilla (1357 y 1359), Movilla (1357), Piérnigas (1385 y 1400), Quintanarnz (1391), Arconada (1391) y Poza (1393). Villas en otras zonas: Talavera (1272), Herrera de Valdecañas (1399) y Caracena (1399). Villas sin identificar: Monasterio (1207), Rubios de Broa (1209 y 1219), 
servado un total de 12 documentos que recogen transacciones de propiedades en la ciudad; dos de ellos corresponden a lo que vengo calificando como momento de la dotación inicial y parecen relacionados con la instalación del convento; el resto datan de la segunda mitad del siglo XIV — seis de ellos corresponden al período entre 1370 y 1400 - y varios están relacionados con la reconstrucción de la iglesia y convento, derruida tras la guerra civil que llevó al trono a Enrique II ${ }^{12}$. Por tanto, no parece que el convento llegara a tener un patrimonio urbano muy importante, como fue el caso de otras instituciones, como el cabildo de Burgos o el monasterio de San Juan, y el grueso de su dominio estaba formado por bienes rurales. Este hecho es especialmente interesante si tenemos en cuenta que muchos de sus benefactores fueron miembros de la oligarquía urbana burgalesa. Las zonas donde las propiedades del convento de la Trinidad eran más abundantes eran La Bureba y la zona de Ubierna. En la primera de estas zonas el convento disponía de heredades en unos 15 lugares y en la segunda en otros 10 . Además, en ambas zonas se localizan los lugares donde, a juzgar por la documentación conservada la presencia del convento era más elevada o, al menos, fue más frecuente; son lugares como Mata, Quintanarrío o Vedecilla. En el valle contiguo al del Ubierna, el del Urbel, los intereses del convento también eran reseñables, así como en la zona de Muñó. En ambas zonas el convento disponía de heredades en cinco lugares. En las zonas más próximas a la ciudad dispuso de heredades en seis lugares, pero en tres de ellos no obtuvo las propiedades hasta muy tarde, en 1400. El convento llegó a tener heredades en zonas bastante alejadas, como Talavera, aunque desconozco si las conservó durante mucho tiempo. En conjunto, cabe deducir la impresión de un dominio relativamente compacto y centrado en zonas cercanas a la ciudad de Burgos al norte del Arlanzón.

El dominio se fue formando sobre todo mediante donaciones, según ya he indicado, procedentes básicamente de miembros de la oligarquía

San Lázaro (1207-1210), Villaescusa (1207-1210), Castro (1207-1210, Tunilla (1209 y 1219), Gal (1209 y 1219), Gosmedos (1209 y 1219), San Emeterio (1209 y 1219), Navillas (1271), Santa Eufemia (1272) y Olmillos (1334).

${ }_{12}$ La primitiva iglesia, situada junto a la muralla cerca de la puerta de San Gil, facilitaba que la muralla fuera asaltada por esa zona; en 1371 la comunidad obtuvo un nuevo emplazamiento junto al anterior para levantar una nueva iglesia cuya construcción estaba en marcha en 1390 . Textos relativos a la reedificación de la iglesia en Trinidad, docs. 116 y 149; otros incluyendo cambios de propiedades por ese motivo en Trinidad, docs. 105 y 154 , y otras adquisiciones en la ciudad en Trinidad, doc. 4 de 1207, doc. 6 de 1207/10, doc. 92 de 1354 , doc. 98 de 1358 , doc. 102 de 1366, doc. 114 de 1371, doc. 131 de 1375, doc. 143 de 1386, doc. 145 de 1387 y doc. 193 de 1400 . 
ciudadana y de miembros de la nobleza, tanto de la alta nobleza como de la nobleza regional castellana. Resulta significativo que el convento no recibiera en ningún caso heredades mediante donaciones regias. En 1207 Alfonso VIII se limitó a confirmar otras donaciones, pero no entregó nuevos bienes al convento ${ }^{13}$. Los reyes posteriores le otorgaron su protección en sentido genérico y ordenaron que se respetaran sus privilegios y se le permitiera ejercer sus funciones asistenciales, pero tampoco añadieron nuevos bienes al dominio ni concedieron rentas regias ${ }^{14}$. Algunos de los donantes levantaron capillas en la iglesia del convento y solicitaron ser enterrados en ellas. La influencia religiosa se traducía así en bienes materiales para los trinitarios. Merece la pena señalar que muchos de los ciudadanos burgaleses entregaron al convento propiedades rurales, quizá porque así lo preferían los frailes. En cualquier caso, es un elemento más que muestra la ya conocida proyección rural de la oligarquía burgalesa ${ }^{15}$. En relación con los enterramientos y la recepción de donaciones por ello, se sitúan algunos de los principales problemas que tuvo el convento con otras instituciones eclesiásticas ${ }^{16}$. Entre los miembros de la nobleza que favorecieron al convento destacan algunos miembros del grupo familiar de los Rojas, que fundaron, dotaron y con frecuencia se enterraron en la capilla de Santa María Magdalena. Al principio las relaciones entre los Rojas - importantes propietarios en La Bureba- y el convento fueron conflictivas ${ }^{17}$, pero durante la segunda mitad del siglo XIII y el siglo XIV se conocen al

13 Trinidad, doc. 5.

${ }^{14}$ Trinidad, docs. 17, 45, 49, 50, 56, 101 y 104. La participación del convento en rentas regias fue escasa, tardía y mediante cesiones de algunos nobles, no de los reyes; así recibió en 1393 de manos de dona Juana de Toledo, viuda de Sancho Sánchez de Rojas, 2.000 maravedies en las rentas de las salinas de Poza; la donación era parte de los 3.500 maravedies de la merçet perpetua que la donante había recibido de manos del rey Enrique II; Trinidad, doc. 164. De manera similar, el convento recibió en 1399 de manos de Sancho Fernández de Tobar 600 maravedíes anuales en las martiniegas de su villa de Caracena; Trinidad, doc. 178.

15 Ruiz (1981), pp. 120-144 y 166-170, Casado Alonso (1985) y Casado Alonso (1987), pp. 451-510.

${ }^{36}$ En 1221 llegaron a un acuerdo el convento y el obispo Mauricio que limitaba la actuación de los trinitarios a no interferir los derechos de las parroquias vecinas; Serrano (1922), pp. 88-89, y Trinidad, docs. 14 y 15. En 1342 hubo un pleito con el cabildo también, entre otras cosas, por la cuestión de los enterramientos; Trinidad, docs. 76-78. En 1389 se desarrolló otro pleito con los clérigos de la iglesia de San Esteban al negarse el convento a pagar una cierta cantidad anual por estar asentado en terrenos de la parroquia; la cantidad a pagar era muy pequeña, 15 maravedíes, y evidentemente el pleito es reflejo de otros problemas de tipo eclesiástico; Trinidad, doc. 152.

${ }_{17}$ Destaca el entramiento de los bienes del convento en la villa de Rojas realizado por Diego Alfonso de Rojas, quien reclamaba bienes que habían vendido al convento Rodrigo 
menos siete donaciones realizadas por miembros de este grupo familiar ${ }^{18}$ y algunos de ellos disfrutaron de importantes bienes propiedad del convento ${ }^{19}$.

A diferencia de lo que sucede con otros propietarios eclesiásticos importantes, no hay indicadores que permitan suponer que el convento viviera momentos de crisis —en lo que a su dominio se refiere - en las últimas décadas del siglo xIII y durante la primera mitad del xIv; no hay un estancamiento en el proceso de expansión del dominio. Tampoco se conocen, en su caso, episodios de encomiendas de bienes por nobles poderosos en la segunda mitad del xIV. Es éste, quizá, el elemento más llamativo del convento de la Trinidad, cómo una nueva institución eclesiástica logra formar un dominio rural importante en momentos de crisis y conflictos. Otros elementos de interés serían los relativos a la cabaña ganadera del monasterio. No hay documentos regios permitiendo a los ganados de la Trinidad de Burgos pastar por el reino libres del pago de montazgos, por ejemplo. Eso parece indicar que el convento no dispuso de una cabaña ganadera de consideración ${ }^{20}$. Eso también lo diferencia de otras instituciones eclesiásticas similares. En segundo lugar, su dominio se extendió por áreas fuertemente señorializadas. Una revisión rápida de las características del dominio como la que pretendo aquí no permite adentrarse en los matices de la diferente composición de los bienes que obtuvo el convento y tampoco la documentación conservada es suficientemente explícita en muchas ocasiones. Pero mi impresión es que en todos los casos el convento obtuvo derechos de propiedad sobre tierras en lugares bajo

Díaz de Rojas y su hijo Diego Ruiz, resuelto favorablemente al convento en 1223; Trinidad, doc. 16.

1* En 1262 Rodrigo Díaz de Rojas y su mujer dieron heredades en Los Tremellos y Pedrosa de Río Urbel; Trinidad, doc. 27. En 1309 Juan Rodriguez de Rojas y su mujer entregaron bienes en Hornillos del Camino; Trinidad, doc. 48. Ya antes, en 1299, Juan Fernández de Rojas habia hecho otra donación en Carcedo de Yuso, en La Bureba; Trinidad, doc. 35. Se conservan dos noticias de donaciones de Juan Rodriguez de Rojas en Quintanilla en La Bureba en 1347 y 1367; Trinidad, docs. 88 y 103. En 1387 Juana de Toledo, hija de Diego Garcia de Toledo y mujer de Sancho Sánchez de Rojas, entregó heredades en Piernigas, en La Bureba, y en 1393 entregó una renta anual de 2.000 maravedies en las salinas de Poza; Trinidad, docs. 142 y 164.

${ }^{10}$ Fernán González de Rojas disfrutó durante su vida de un número importante de bienes del convento, que después fueron devueltos por sus hijos en 1271; Trinidad, doc. 30 .

21 Sin embargo, aunque quizá no dispusiera de una gran cabaña, el convento sí tenía rebaños en algunos lugares, como Quintanarrio; Trinidad, doc. 91 de 1353. Otros textos mencionan a los pastores del convento, lo que también indica la existencia de rebaños; Trinidad, doc. 104 de 1368. 
el señorío de otras instituciones eclesiásticas o de nobles laicos. Es posible deducirlo a partir de una fuente como el Becerro de las Behetrias, que registra la condición señorial de muchos de los lugares donde tenía propiedades el convento sin indicar, en ningún caso, derechos de señorío en sus manos, ni siquiera en aquellos lugares donde los intereses patrimoniales del convento parecen más intensos ${ }^{21}$. Lamentablemente el texto del Becerro de las Bebetrias que se ha conservado no ofrece información sobre La Bureba, donde el convento centraba una parte de su dominio, pero no creo que en esta zona las condiciones generales de formación del dominio fueran diferentes que en el resto. El convento fue, por tanto, un gran propietario, uno de los más importantes de la zona, pero no fue señor en sentido estricto, no obtuvo derechos de ejercicio de señorío en las villas donde tenía propiedades.

\section{EL DOMINIO DEL CONVENTO DE SANTO DOMINGO DE CALERUEGA}

Desde las primeras décadas del siglo xIII existía en la villa de Caleruega un hospital bajo la advocación de Santo Domingo. Los hagiógrafos e historiadores de la orden consideran a Caleruega como el lugar de donde era originario el fundador de la orden de Predicadores. Algo más al sur, en San Esteban de Gormaz, existía también a principios del siglo XIII un monasterio femenino, quizá de monjas canónigas agustinas, con la advocación de Santa Maria de Castro. No es mucho lo que se conoce de ese monasterio, que hacia 1218 ó 1219 debió quedar vinculado a la orden de Santo Domingo. El hospital de Caleruega y el monasterio de San Esteban de Gormaz fueron la base que sirvió al rey Alfonso X para fundar en 1266 el convento de monjas dominicas de Caleruega, de cuyo dominio me ocuparé en las siguientes páginas ${ }^{22}$. Para la fundación, el rey trasladó a las monjas de San Esteban a Caleruega y dotó al nuevo convento con

21 Véase Martínez Diez (1981).

${ }^{22}$ La documentación fue publicada por Martínez Liébana (1931) (en adelante citaré Caleruega); el autor incluyó una extensa introducción sobre la historia del convento. Recientes conmemoraciones se han plasmado en varias publicaciones como González González (1993); Aniz Iriarte y Diaz Martín (coords.) (1994), (1995) y (1996), que incluyen contribuciones de un valor diverso. Por otro lado, la abundante bibliografía hagiográfica no es de interés para este trabajo. Sobre la orden de predicadores, en general, véase Garcia Villoslada (dir.) (1982), pp. 136-142, y bibliogafía en pp. 119-121; Palacios Martín (1996); y para una recopilación bibliográfica reciente Sáenz de Haro (1996). Entre los estudios de los dominios 
la propia villa de Caleruega ${ }^{23}$. Por tanto, a partir de la fundación el convento contaba con las propiedades anteriores del monasterio de Santa María de Castro, con las del hospital de Caleruega y con la villa de Caleruega. El dominio anterior del monasterio de Santa María de Castro, a juzgar por la documentación que se ha conservado, consistía de algunas heredades en San Esteban de Gormaz y sus aldeas, mientras que el hospital disponía de algunas propiedades en la villa de Caleruega ${ }^{24}$. La adquisición de la villa de Caleruega merece un comentario específico porque la villa no era realengo sino behetría, y previamente a su donación al convento el rey tuvo que obtener el señorío sobre el lugar, adquiriendo las divisas en manos de los diviseros, que eran algunos de los principales ricos hombres del reino. Me he referido a ello en otras ocasiones y no me detendré ahora. Sólo indicaré que el proceso fue relativamente largo $-\mathrm{y}$ seguramente costoso para el rey-. Entre la documentación del convento se conservan los textos de donación de las divisas por los diviseros al rey Alfonso ${ }^{25}$.

La expansión patrimonial del convento, la formación de su dominio, se realiza fundamentalmente en el período entre 1270 y 1360 . A lo largo de esos noventa años el convento adquirió el grueso de su dominio, que

de otros conventos dominicos destaca el de García García (1986), sobre el convento fundado por don Juan Manuel.

${ }^{23}$ El privilegio de fundación lleva la fecha de 4 de junio, y el 31 de octubre don Gómez de Monzón, por orden del rey, dio posesión de la villa de Caleruega a doña Toda Martínez, priora del monasterio de San Esteban «que mando y venir el prior pvcial» (sic); Caleruega; docs. VIII y IX.

${ }^{24}$ Además de heredades, el monasterio de Santa María de Castro había recibido algunos privilegios regios. En 1229 Fernando III le había concedido exención de portazgo en todo el reino; Caleruega, doc. I. En 1242 autorizó a tener tres yugadas de tierra, 30 aranzadas de viña y dos aranzadas de huerta procedentes del realengo; Caleruega, doc. III. En 1262 Alfonso X amplió esas heredades en tres yugadas más; Caleruega, doc. VI. Mientras tanto, en 1258 el monasterio había adquirido otras heredades en Morcuera, aldea de San Esteban, en 1260 compró un huerto en San Esteban, recibió una viña en la misma villa en un momento que no conocemos y en 1263 hizo una adquisición importante al comprar a Martín González y su mujer por mil maravedies todo lo que tenían «en termino de Sant Esteban de los adarves a fueras; Caleruega, docs. CCXVII, CCXXII, CCXXVIII y CCXXIX. En cuanto a la iglesia y hospital de Caleruega, en 1237 Fernando III, «ob reverentiam beati Dominici confessoris de Caleruega», concedió exención de todo tributo regio para «illo bomo qui moratus fuerit in suo bospitali, quod est circa suam Ecclesiam in Caleruega, quicumque sit ille»; Caleruega, doc. II. Y en 1248 doña Urraca García vendió al obispo de Osma, para la iglesia de Santo Domingo y el hospital, heredad en Caleruega por 300 maravedíes; Caleruega, doc. CCXVII.

${ }^{25}$ Ese proceso duró, al menos, hasta 1274. En la documentación del convento se han conservado 14 textos que recogen las donaciones de los diviseros al rey; Caleruega, docs. CCXXX a CCXLII y CCXIVIII. Sobre esto véase también Álvarez Borge (1996), pp. 269-270. 
se extendió por unas 35 villas, la mayor parte de las cuales se localizaban en la merindad de Silos y en las zonas de San Esteban de Gormaz y Soria. Más adelante describiré los rasgos generales del proceso de adquisición de heredades, pero previamente es necesario considerar el importantísmo apoyo recibido por el convento de los sucesivos reyes ${ }^{26}$. Un reflejo claro del apoyo regio se expresa en el hecho de que entre los documentos conservados del convento para el período entre 1266 y 1390 figuran más de 90 textos expedidos por los reyes de Castilla. Por supuesto no todos esos documentos recogen nuevas donaciones de heredades o de rentas para el convento, muchos son confirmaciones o tienen que ver con pleitos, pero es buen dato que muestra el interés de los reyes por el convento.

Alfonso $\mathrm{X}$, el rey fundador, continuó beneficiando al convento aunque la forma de concretarse su apoyo fue más mediante la entrega de rentas, exenciones y privilegios que con la entrega de heredades. Estas últimas se limitan a la casa de Bañuelos de la Calzada, en 1273, que el rey había adquirido previamente el año anterior del monasterio de Silos a cambio de entregarle parte de las martiniegas de varias villas de la zona ${ }^{27}$, y al permiso, en 1277, para que adquiriera 30 yugadas de heredad en el realengo cerca del convento, pero en varios lugares, no en uno sólo ${ }^{28}$. Más importantes fueron otras concesiones. Ya en 1270 ordenaba el rey a dos nobles de la zona que amparasen y defendiesen a los vasallos del convento en Castilla ${ }^{29}$, y ese mismo año le concedía exención de portazgo en todo el reino para los productos de consumo en el convento, excusaba de las rentas regias a todos los yugueros, pastores, hortelanos y otros paniaguados del convento, concedía privilegios de pastos en todo el reino, hacía exentas las heredades que adquiriera y le entregaba una renta anual de diez cahices de sal en las salinas de Añana ${ }^{30}$. Este bloque de privilegios fueron ratificados después por el mismo rey, pero todavía hizo Alfonso $\mathrm{X}$ nuevas concesiones; en 1277 ordenó que todos los que tuvieran heredades en Caleruega pechasen por ellas en los tributos regios de la villa aunque fueran moradores en otros lugares; ese mismo año también dispuso que hubiera mercado semanal los jueves en Caleruega; en 1279 concedió una renta de 1.300 maravedíes en las martinegas de Maderuelo, y en 1281 confirmó

\footnotetext{
${ }^{26}$ Sobre ello, véase Caleruega, pp. LI-LXXXI.

${ }^{27}$ Caleruega, docs. XX y XXI.

28 Caleruega, doc. XXX.

${ }^{29}$ Caleruega, doc. XI.

"Caleruega, docs. XII, XIII y XVI, XIV, XV, XVII y XVIII.
} 
haber concedido al convento todas las rentas regias de la villa de Caleruega, aunque en ratificaciones posteriores se exceptuará la moneda forera ${ }^{31}$.

Muerto Alfonso X, Sancho IV pondrá fin al conjunto de concesiones regias más importantes entregando en 1284 las tercias regias de pan, vino y menudo de los Arauzos, Quintanarraya y Huerta del Rey, eximiendo al convento del pago de derechos de cancillería en 1286 y permitiendo que las monjas pudieran heredar de sus padres en $1287^{32}$. A partir de ese momento la actuación de este rey y de sus sucesores se centró en la confirmación de todos los privilegios que habían sido concedidos con anterioridad y en la defensa de los derechos contenidos en ellos. Con posterioridad la relación de los sucesivos reyes con el convento se concretará en dos aspectos nuevos. Uno es la concesión, ya en 1388, del lugar de Villajimeno, "que es cerca de Caleruega que es lugar dado por yermo» ${ }^{33}$. $\mathrm{Y}$ otro son los diversos cambios en las rentas concretas sobre las que se asignaron algunas cantidades importantes al convento. Los 1.300 maravedíes concedidos por Alfonso X en las martiniegas de Maderuelo en 1279 fueron cambiados por Sancho IV por 7.000 maravedíes en las salinas de Añana, Poza y Rosío ${ }^{34}$. Probablemente fue dificultoso para el convento recaudar esta renta, que desde 1302 debía pagarse en sal ${ }^{35}$. En todo caso, en 1309 Fernando IV la cambió por el portazgo de Medina del Campo y 2.100 maravedíes sobre el pecho de los judíos de esa villa ${ }^{36}$. A fines del siglo XIV hubo nuevos cambios; Juan I dio Medina del Campo a la duquesa de Lancaster, y con ese fin cambió en 1389 las rentas que tenía ailí el convento por otras de igual cantidad en el pecho de los judíos de Burgos ${ }^{37}$, y todavía en 1396 Enrique III volvió a cambiarlas, situándolas en las salinas de Atienza, donde el convento poseía otras desde $1272^{38}$.

Como vemos, la contribución directa de los reyes a la expansión del dominio territorial de Caleruega no fue muy importante, se limitó a la villa de Caleruega, la casa de Bañuelos y el lugar despoblado de Villajimeno,

"Caleruega, docs. XXIII, XXVI y XXVII, XXXI y XXXIII.

${ }^{32}$ Caleruega, docs. XXXVI, XXXIX y XLI.

${ }^{33}$ Caleruega, doc. CX.

${ }^{3-}$ En 1291 se habla de 7.800 maravedíes sobre las martiniegas de Maderuelo, aunque tanto en la concesión de Alfonso X en 1279 como en una confirmación posterior de Sancho IV en 1285 se habla de 1.300; Caleruega, docs. XXXI, XXXVII y XLVII.

${ }^{35}$ Caleruega, docs. LIX y LX, LXIII y LXV-LXVI.

${ }^{36}$ Caleruega, docs. LXVIII y LXIX.

${ }^{37}$ Caleruega, doc. CXI.

${ }^{38}$ Caleruega, doc. CXIV. 
además de parte de las tercias de otras villas cercanas. Esto podría explicarse por el elevado grado de señorialización de la zona ya a fines del siglo xiIr. Sin embago, los reyes concedieron al convento diversas exenciones y le concedieron importantes rentas. De esa manera pudo disponer el convento de dinero para desarrollar una política de compras de heredades que, como veremos a continuación, fue uno de los aspectos más relevantes en el proceso de formación y expansión del dominio. En el Cuadro 2 resumo ese proceso ${ }^{39}$.

\section{CUADRO 2}

Evolución del dominio del convento de Caleruega entre 1267 y 1370

\begin{tabular}{|c|c|c|c|}
\hline Periodo & Donaciones & Compras & Cambios \\
\hline 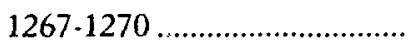 & 1 & & \\
\hline 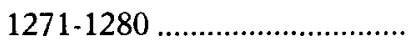 & $4 *$ & 4 & 1 \\
\hline 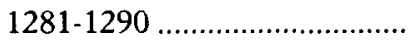 & 1 & 1 & 1 \\
\hline 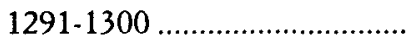 & 1 & 3 & \\
\hline 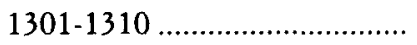 & & 2 & 1 \\
\hline 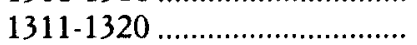 & & 2 & 1 \\
\hline 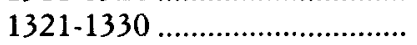 & 3 & & \\
\hline $1331-1340$ & & 1 & \\
\hline 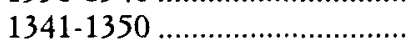 & & 2 & \\
\hline 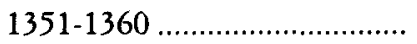 & & $2 * * *$ & \\
\hline 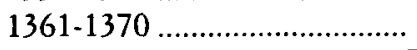 & $1^{* *}$ & & \\
\hline TOTAL....................... & 11 & 17 & 4 \\
\hline
\end{tabular}

* Hay dos documentos que recogen una donación de Juan Pérez de Guzmán en Villajimeno, en 1274, pero con ligeras variaciones. Contabilizo sólo una operación; Caleruega, docs. CCXIVIII y CCXILX.

** Incluyo aquí la donación de Nuño González en Torrecilla en 1362, que repite su mujer en 1381. Caleruega, docs. CCXCI y CCXCIV.

$* * *$ Incluyo como venta la entrega de los bienes de María Díaz en Baños y Gumiel en 1351, que también aparece registrada como donación; Caleruega, docs. CCLXXXI y CCLXXXII.

${ }^{39}$ El cuadro está realizado a partir de los documentos publicados en Caleruega. Me interesa reflejar en el Cuadro el dominio territorial; es necesario tener en cuenta que no incluyo los datos relativos a las donaciones regias ni al proceso de adquisición de divisas en la villa de Caleruega. Ya he mencionado las donaciones regias, que sobre todo consistieron en exenciones y rentas y sólo llevaron a que el convento adquiriera heredades en dos lugares además de Caleruega. En cuanto a esto último, los textos se refieren en unos casos a donaciones de los nobles al rey y en otros casos a donaciones directamente al convento; evidentemente, todo forma parte del mismo proceso. Incluir esos datos creo que distorsionaria las cifras globales. 
Entre 1271 y 1362, período que puede considerarse de manera aproximada como de expansión del dominio, el convento realizó 17 operaciones de compras de bienes, más frecuentes a fines del siglo XIII, pero repartidas más o menos durante todo el período. Un aspecto relevante, en mi opinión, es que el convento tuvo especial interés en comprar tierras en algunos lugares determinados, sobre todo en villas próximas a Caleruega. Así, realizó cinco compras en Baños de Valdearados ${ }^{40}$, dos en Bañuelos ${ }^{41}$ y otras tantas en Valdeande ${ }^{42}$ y en la propia Caleruega ${ }^{43}$. Puede considerarse, por tanto, que el convento tuvo una política sistemática de adquisición de heredades, puesto que 11 de las 17 operaciones de compra se concentraron en cuatro lugares. En cuanto a las donaciones, de las que se conocen 11 operaciones exceptuando las ya citadas donaciones regias, presentan características menos homogéneas. Casi la mitad se realizaron entre 1271 y 1280 y la mayoría de éstas fueron hechas por ricos hombres con propiedades importantes en la zona. Así, Gil Gómez de Roa entregó su casa de Iscar en $1271^{44}$; Juan Pérez de Guzmán dio en 1274 su divisa

${ }^{* 0}$ En 1292 compró a Sancha García, hija de Garcia García de Peñaranda, sus heredades en la villa con «ssolares cassas poblados» (sic) por 1.500 maravedies; Caleruega, doc. CCLXIV. Ese mismo año compró a Diego Fernández de Villanueva sus heredades y derechos en la villa excepto un solar por 6.000 maravedíes; Caleruega, doc. CCLXV. En 1294 Ramiro García y sus hijas vendieron sus heredades por 500 maravedies; Caleruega, doc. CCLXVII. En esta villa recibió además el convento dos donaciones, una en 1293 y otra en 1326; esta última fue realizada por dona Sancha, cuyo nieto, Álvaro Martinez, vendió también al convento otra tierra en Baños en 1347, renunciando a los derechos que pudiera tener sobre los bienes donados por su abuela y recibiendo a cambio un caballo con silla y freno; Caleruega, docs. CCLXVI, CCLXXV y CCLXXXV, respectivamente. Por último, en 1351 volvió el convento a comprar heredades en Baños y en Gumiel procedentes de Mari Díaz por 2.450 maravedies, aunque la relación de este personaje con el convento era más compleja, era la mujer de Juan González de Heredia -que precisamente había comprado heredades en Baños en 1340 por 1.800 maravedíes-, y al morir su marido pidió entrar en el convento junto a su hija Teresa, y en ese contexto se produce la venta; Caleruega, docs. CCLXXXI, CCLXXXVI y CCLXXXVII.

${ }^{41}$ En 1309 compró el convento las heredades de Alvar Pérez de Zazuar por 4.000 maravedíes; Caleruega, doc. CCLXVIII. Ese mismo año compró también las de Rodrigo González de San Esteban por 1.100 maravedies; Caleruega, doc. CCLXIX.

42 En 1311 por 1.000 maravedies y en 1314 por 950 , de Íñigo González de Villanueva y Rodrigo González de Contreras, respectivamente, que probablemente eran parientes; Caleruega, docs. CCLXXII y CCLXXIII.

43 En 1285 compró el convento las heredades de Fernando Ibáñez y su mujer doña Navarra por 8.000 maravedíes; Caleruega, doc. CCLIX. Y en 1344 otras dos tierras de Domingo Pérez; Caleruega, doc. CCLXXXII. Otras villas donde obtuvo el convento heredades mediante compra fueron Quemada (1277), Tubilla del Agua (1277), Cerezo de Arriba (Sepúlveda, 1278), Quintanilla Recuerda, Recuerda y Arauzuelo (1331) y Arauzo de la Torre (1353); Caleruega, docs. XXII, CLIII, CCLXXVIII y CCLXXXVIII.

" Calenuega, doc. CCXIIII. 
en Villajimeno, pero a condición de que los otros ricos hombres que eran diviseros en la villa hicieran lo mismo o el convento lograra ganar sus divisas ${ }^{45}$, y doña Brayda, señora o patrona del convento, le entregó sus heredades en Peñaranda, Iglesias - junto a la anterior-, Coruña del Conde, Henar y Tubilla del Agua para que hicieran un aniversario por el alma de la condesa Teresa ${ }^{46}$. En 1274 debió recibir también el convento la última divisa que le quedaba por adquirir en Caleruega perteneciente a la orden de Santiago ${ }^{47}$. Después siguió recibiendo donaciones durante todo el período, pero de una manera bastante irregular tanto en la frecuencia como en la calidad de los bienes donados y en su ubicación geográfica ${ }^{48}$. Merece una atención especial el conjunto de los bienes que la priora Toda Martínez heredó de sus padres en Soria y San Esteban de Gormaz y que finalmente debieron pasar a manos del convento hacia $1277^{49}$. Esos bienes aumentaron los que ya poseía el convento en esas zonas desde su ubicación anterior en San Esteban y fueron una de las pocas adquisiciones que hizo

45 Caleruega, docs. CCXIVIII y CCXIIX.

* Caleruega, doc. CCLVI. No está del todo claro el papel de este personaje, que probablemente era equiparable al de las señoras de otros monasterios como el de Las Huelgas de Burgos, ni tampoco sabemos quién era realmente. Aparece relacionada con el convento, actuando conjuntamente con la priora, entre 1276 y 1281; sobre ella véase Caleruega, pp. LX-LXI.

${ }^{47}$ Lo que se conoce es la donación de la orden al rey; Caleruega, doc. CCXLVIII; según he indicado, no incluyo esta donación en el cuadro 2. La orden había recibido bienes en Caleruega en 1258 procedentes de Fernando García de Villamayor; Caleruega, doc. CCXIX. En 1270 había adquirido también el convento la parroquia de Caleruega por donación del obispo de Osma y en 1272 llegó a un acuerdo con un clérigo de la villa por el que éste daba al convento unas casas, renunciaba a la parte que le correspondía en la iglesia de San Sebastián y se comprometía a atender una capellanía; el convento a cambio le daría una renta en especie y en moneda para mantenerle durante su vida; Caleruega, docs. CXCVII y CCXLIV.

${ }^{4}$ Ya he mencionado dos donaciones en Baños de Valdearados en 1293 y 1326; Caleruega, docs. CCLXVI y CCLXXV. En 1286 el convento recibió otra donación, posiblemente importante aunque no conocemos su contenido preciso, procedente de Aldonza Rodríguez de Saldaña, mujer de Nuño Gil de Aza, y sus hijos; Caleruega, doc. CCLX. En el siglo XIV, en 1322 recibió heredades en Hontoria de Valdearados procedentes de Pedro García de Alcoba y su mujer a cambio de proporcionarles enterramiento, y en 1326 en Caleruega de unos vecinos de la villa; Caleruega, docs. CCLXIV y CCLXXVI. En 1353 obtuvo unas casas en Burgos por donación testamentaria; Caleruega, doc. CCLXXXIX, aunque este documento recoge el pleito con los herederos del donante sabemos que finalmente obtuvo la propiedad de esas casas, que se documentan en Trinidad, docs. 111 y 113. Por último, en 1362 obtuvo heredades en Torrecilla de los Caballeros por donación de Nuño González, vecino de Aranda, aunque el donante se reservó el usufructo de los bienes, que a su muerte tampoco pasaron a manos del convento, puesto que siguió disfrutándolos su viuda para compensar una deuda de 10.000 maravedies que tenía con ella su marido; sobre la donación y los personajes, Caleruega, docs. CCXC, CCXCI y CCXCIII-CCXCV.

"Sobre ello véase Caleruega, docs. CCXLV, CCL y CCLII. 
allí el convento después de su traslado a Caleruega. Precisamente en San Esteban y en sus aldeas tuvieron lugar casi todos los cambios que hizo el convento, que, por otra parte, fueron escasos ${ }^{50}$.

El proceso de evolución del dominio de Caleruega puede quedar descrito así en su líneas generales, pero con la reserva siempre de que la documentación conservada puede reflejar sólo parcialmente la realidad. Había otras villas donde tuvo intereses el convento cuya procedencia nos es desconocida. El Becerro de las Behetrias indica que disponía de la facultad de ejercer el señorío de manera exclusiva en Caleruega y compartiéndolo con otros señores laicos y eclesiásticos en Espinosa de Cervera ${ }^{51}$. Los derechos sobre Caleruega son claros desde 1266, pero nada sabemos sobre la adquisición de los intereses en Espinosa ${ }^{52}$. Algo similar sucede con Villacienzo, cerca de Burgos; sabemos que el convento tenía bienes allí, puesto que pleiteó por ellos con el hospital del Rey en 1393, pero no sabemos cuándo los adquirió ${ }^{53}$.

Además de su dominio territorial y de la participación en las rentas regias —que a su vez fue lo que le permitió adquirir buena parte de sus heredades-, la tercera fuente de ingresos del convento de Caleruega procede de su cabaña ganadera. Como otros monasterios de la zona, el convento dispuso de una cabaña ganadera importante, aunque lamentablemente las fuentes de que disponemos para su estudio resultan insuficientes. Conocemos su cabaña ganadera, como en muchos otros casos, a través de los privilegios de pastos y exenciones que le concedieron diversos reyes,

51) En 1278 recibió el convento heredades en Fines y en Rejas (aldeas de San Esteban) de Martín Ramírez de Soria, dándole otras en Maltoso (aldea de Soria); Caleruega, doc. CCXV. En 1290 cambió unas heredades en San Esteban con el concejo de la villa y en 1310 otras con Sancho García de Peñaranda; Caleruega, docs. CCLXIII y CCLXX. Por último, el año siguiente, 1311, dio el convento unas viñas en Peñaranda a Muño Fernández de San Esteban y recibió otras en Hontoria de Valdearados; Caleruega, doc. CCLXXI.

"Martínez Diez (1981), XV-20 y 108.

52 En 1274 llegaron a un acuerdo los concejos de Espinosa y Caleruega en el pleito que tenían sobre lo que debían pagar los vecinos de una villa por las heredades que tuvieran en la otra; pidieron al abad de Silos -que poseía intereses en Espinosa- y a fray Domingo de Caleruega que pusieran sus sellos en el documento correspondiente, pero no puede deducirse que el convento de Caleruega tuviera ya intereses en Espinosa; véase Caleruega, doc. CCXLVI. El convento adquirió sus derechos señoriales en Espinosa antes de 1326; en esa fecha, Fernando de Haro, hijo de Diego López de Haro y de la infanta Violante, tomó bajo su protección al convento, mandando a sus vasallos y merinos que defendieran sus bienes $e$ a los sus vasallos de Caleruega e a los que an en Espinosa de Cervera, Caleruega, doc. LXXXIV.

${ }^{53}$ Obtuvo además el convento el reconocimiento de sus derechos; Caleruega, doc. CCXCVI, p. 386. 
pero apenas disponemos de más datos que nos permitan valorar los ingresos que obtenía el convento por esa vía. Ya en 1270 Alfonso X concedió que sus ganados pudieran pastar libremente por todo el reino, igual que los ganados del rey, pero sin cuantificar la cantidad de ganado a que se refería el privilegio. El mismo rey renovó esa concesión en términos muy similares en 1277 . Ya en 1289 , al confirmar los privilegios de pastos, Sancho IV ofreció una primera cuantificación; la libertad de pastos se concedió entonces para 200 vacas, cinco yeguas y 2.000 ovejas del convento. El mismo rey en 1295 cifró la cabaña del convento libre de cargas en cantidades más altas: 1.000 vacas, 10.000 ovejas, 1.000 cerdos y 50 yeguas. Cuando Fernando IV confirmó los privilegios de los reyes anteriores, en 1310, lo hizo refiriéndose a 10.000 ovejas, 500 cabras, 1.000 vacas, 1.000 cerdos y 200 yeguas; las mismas cifras que encontramos en otra confirmación de Alfonso XI en 1318. No se consevan más textos referidos a este asunto hasta que en 1390 Juan I confirmó los privilegios de pastos, pero esta vez para 2.000 ovejas, 200 vacas, 500 cabras, 100 cerdos y 50 yeguas ${ }^{54}$.

Podría avanzarse en la interpretación de esas cifras considerando la posible evolución de la cabaña ganadera del convento. Pero también sería necesario un análisis diplomático de los textos conservados. Por ahora resulta suficiente constatar que el convento pudo disponer de una cabaña ganadera considerable que, sin duda, le proporcionaría ingresos importantes que no podemos cuantificar. Tampoco es posible cuantificar otra vía de ingresos: las dotes de las monjas. Algunas de las donaciones que he mencionado lo fueron a cambio de la admisión en el convento - de las donantes o de sus hijas-, pero sin duda hubo otras dotes en metálico que no quedaron reflejadas en documentos que se hayan conservado. Lo que sí es claro es que el convento se convirtió pronto en un foco de atracción para las mujeres nobles de la zona. En 1288 el Maestro General de la orden de predicadores ordenó que no hubiera más de 50 monjas en el convento de Caleruega, cifra que se aumentó a 60 en 1331, pero indicando que con ello se trataba de reducir el número de monjas que efectivamente había entonces en el convento ${ }^{55}$.

El número de monjas indica el éxito religioso del convento, pero, indudablemente, también es expresivo del éxito económico de la fundación dominica. En efecto, no parece que las propiedades y derechos del convento

${ }^{54}$ Pueden verse los textos de referencia en Caleruega, docs. XV, XXV, XIVI, LI, LXX, LXXVI y CXII.

"Saleruega, docs. CCLXII y CCLXXVII. 
se vieran amenazados seriamente en momentos que, para otras instituciones eclesiásticas, suelen definirse en términos de crisis. Por supuesto el convento tuvo que pleitear con particulares e instituciones diversas en defensa de lo que consideraba sus derechos y privilegios ${ }^{56}$, pero del conjunto de pleitos sólo me parecen relevantes dos. Por un lado, todo el bloque de pleitos para conseguir hacer efectivo el cobro de las rentas regias cedidas y situadas primero en varias salinas y después en el portazgo de Medina del Campo ${ }^{57}$. $\mathrm{Y}$ por otro lado, el conflicto que enfrentó al convento con sus vasallos de la propia villa de Caleruega a mediados del siglo XIV ${ }^{58}$. Pero las dificultades en la recaudación de las rentas regias se solucionaron resituando las rentas, como he indicado, y una sentencia arbitral en 1346 puso fin a las pretensiones de sus vasallos de Caleruega ${ }^{59}$.

\section{EL DOMINIO DEL CONVENTO DE SANTA CLARA DE ASTUDILLO}

El tercer ejemplo que quiero analizar es el convento de Santa Clara de Astudillo, fundado hacia 1354 por María de Padilla, amante del rey Pedro $I^{60}$. Como en los otros casos que he mencionado, para el convento de Santa Clara de Astudillo se ha conservado una documentación significativa que permite reconstruir, aunque sea de forma aproximada, el dominio territorial que daba sustento material a la fundación conventual ${ }^{61}$. El

${ }^{56}$ Textos que recogen pleitos o conflictos con oficiales regios, en Caleruega, docs. LXII, LXXXI, LXXXV, XCII y CCLXXX; con otros señores o propietarios, en docs. XIII, LXXXIV, CCLXXXIX y CCXCVI; con otros eclesiásticos, en docs. CCII, CCIII y CCLVIII, y relativos a términos y límites de sus villas con otras, en XIX, CCXLVI y CCXCVII.

${ }^{57}$ Caleruega, docs. LXIII, LXV, LXVI, LXVII, LXVII, LXXV, LXXVIII, LXXXVIII, XCVIII, CIV y CIX.

s8 Sobre ello, Álvarez Borge (1993), pp. 16-18.

59 Caleruega, doc. CCLXXXIV.

${ }^{60}$ Sobre el reinado de Pedro I, y con relación al papel de María de Padilla, se han publicado varias monografías recientemente: Estow (1995), Díaz Martín (1995) y García Toraño (1996).

6) Simón y Nieto (1896) (en adelante citaré Simón, «Astudillo») publicó o regestó un total de 58 documentos, casi todos del siglo XIV, algunos relacionados directamente con el convento y otros con la fundadora y su familia. Posteriormente se publicó Orejón Calvo (1917); esta obra, refundida con otra del autor sobre la villa de Astudillo, ha sido reeditada por la Diputación de Palencia en Orejón Calvo (1983 y 1984); la reedición consta de dos volúmenes: el vol. I incluye los estudios anteriores de la historia de la villa y del convento, y el vol. II los apéndices documentales de ambos (en adelante citaré Orejón, Astudillo, I y II, refiriéndome a la edición más reciente). El Apéndice II del vol. II, único que citaré en este trabajo, está a su vez dividido en otros dos con textos relativos al convento y algunos 
convento de Santa Clara dispuso de un pequeño dominio territorial mediante la dotación inicial de la fundadora; además recibió algunas donaciones de otros miembros de su familia y, al igual que el convento de Caleruega, obtuvo un volumen significativo de rentas regias situadas en diversos lugares.

El proceso de dotación por la fundadora se realizó entre 1355 y 1357 , aunque en todo momento, mediante su calidad de patrona del convento, María de Padilla se reservó un control estrecho sobre los bienes que cedía ${ }^{62}$. En 1355 entregó al convento el lugar de Cubillas de Cerrato, que había comprado a su tío Juan Fernández de Hinestrosa con las rentas y derechos que le había entregado el rey; la heredad que había comprado en Astudillo a doña Mencía López, hija de Diego López de Torquemada y viuda de Pedro Díaz de Cabuérniga, así como las otras tierras, viñas y aceñas que tenía ella en la villa, y las heredades que fueron de su padre, Juan García de Padilla, que le correspondían tanto por herencia como por compra a su hermano Diego García, aunque de este último bloque se exceptúan las casas fuertes y los vasallos de Juan García en algunos lugares, «que finquen pa en mi linaje» ${ }^{63}$. La documentación conservada en el archivo del convento permite conocer bastante bien el origen de estos bienes. La villa de Cubillas había pertenecido a la orden de Santiago, adquiriéndola Alfonso XI con otras muchas en 1345 para entregársela a su notario mayor, Fernán Sánchez de Valladolid; entre 1352 y 1355 éste la vendió a Diego García de Padilla y a María González, el hermano y la madre de doña María, quienes a su vez enajenaron Cubillas a Juan Fernández de Hinestrosa y, por último, éste a su vez la vendió a doña María el 6 de abril

otros relativos a los Padilla. Además de los 48 documentos publicados o regestados por Simón y Nieto, Orejón publicó otros 23 - repitiendo cuatro regestados por el anteriorrelativos al convento y siete relativos a los Padilla. Sobre los monjes franciscanos y las monjas clarisas puede verse Garcia Oro (1988), donde sin embargo no se hace referencia al convento de Santa Clara de Astudillo. También VV.AA, (1994), A. Rucquoi (1996) y C. Rodríguez Núñez (1996). Los estudios concretos de conventos de clarisas son relativamente abundantes, para una bibliografía reciente véase Sáenz de Haro (1996).

${ }_{62}$ El patronato que ejercía la fundadora fue reconocido expresamente por el legado pontificio en 1356; véase Simón, «Astudillo», doc. 4; también Orejón, Astudillo, II, docs. 5,6 y 9. Pero ya antes, como se ve en el documento de dotación del año anterior, ella declaraba que wde todo esto que dicho es retengo pa mi en mis dias que yo que vea todas las rentas desto que dicho es e mande e ordene en que manera se den en mantenimiento de la dicha abadessa e convento...»; Simón, «Astudillo», doc. 16. Sobre la fundación y dotación del convento, sobre todo centrado en las cuestiones eclesiásticas, Orejón, Astudillo, I, pp. 206-214.

63 Simón, «Astudillo», doc. 16. 
de 1355, entregándole el rey los pechos y derechos regios en la villa el 5 de mayo ${ }^{64}$. Los bienes de Mencía López en Astudillo fueron adquiridos por María de Padilla también unos meses antes en un bloque más amplio en el que se incluían heredades en otras siete villas próximas ${ }^{65}$. Lo que no sabemos es si las heredades de las otras villas pasaron también a manos del convento o no ${ }^{66}$. En cuanto a los bienes procedentes de Juan García de Padilla, la expresión utilizada por doña María en 1355 es muy vaga, aunque documentos posteriores permiten pensar que sólo cedió una parte pequeña de la herencia de su padre. La viuda de Juan García, María González, y sus hijos legítimos, Diego García y María, se repartieron la herencia que les correspondía en 1351, recibiendo los hijos heredades en unas 14 villas, que debían repartirse por mitades ${ }^{67}$. En 1354 María de Padilla compró a su hermano Diego por 60.000 maravedíes varias propiedades en Astudillo, Cordovilla, Villamediana y Vallegera, algunas procedían de la herencia de su padre y otras habían sido adquiridas por Diego García a Garcí Laso de la Vega ${ }^{68}$. Sólo una parte de todos esos bienes pasaron después a manos del convento.

En 1356 María de Padilla hizo un nuevo documento de dotación del convento de Santa Clara más amplio y mucho más detallado ${ }^{69}$. Entregaba

${ }^{6}$ Véase Moxó (1973), pp. 133-134 y docs. 5 y 6. El primer documento de dotación del convento de Santa Clara es de 10 de junio de 1355. El Becerro de las Bebetrías todavía registra el señorío de Fernán Sánchez de Valladolid: Este logar fue dado del rey don Alfonso e del maestre de Santiago a don Fernando Sanchez de Valladolid; es solariego; Martínez Díez (1981), I-31.

${ }^{65}$ La compra fue hecha por el mayordomo de doña María de Padilla, Juan González de Pedrosa, por 40.000 maravedíes e incluía las casa de doña Mencía en Astudillo en el barrio de Santa María y las heredades de Santoyo, Torre, Palacio, Villasilo, Villalaco, Villodre y Melgar de Yuso; Simón, «Astudillo», doc. 28. Unos años antes, las heredades de Astudillo fueron objeto de un pleito entre la reina dona María, madre de Pedro I, y los herederos de Pedro Díaz de Cabuérniga a propósito de una deuda de éste con la reina en la que esas heredades habían sido puestas como garantía; Simón, «Astudillo», doc. 12.

${ }^{66}$ Como veremos más adelante, el año siguiente doña María dirá que las heredades procedentes de doña Mencía en Astudillo podian rendir 80 cargas anuales, aunque tanto en 1355 como en la entrega hecha por su despensero hacia 1357 parece hablarse de solares urbanos.

${ }^{67}$ En algunas de las villas los compartían con su madre; en todo caso hay que pensar que los bienes objeto del reparto no fueron todos los que tuvo Juan García, pues algunos otros debieron pasar a sus hijos ilegítimos, dos de los cuales actuaron como repartidores; Simón, «Astudillo», docs. 53, 54, 55 y 56.

${ }_{68}$ Se trataba de las aceñas sobre el Pisuerga que fueron de Garci Laso de la Vega, su parte en otras aceñas viejas y, además, otras tierras, torres y casas en Astudillo y también las heredades de Diego en Cordovilla, Villamediana y Vallegera -estas últimas son las que deben proceder de la herencia de su padre-; Simón, «Astudillo», doc. 57.

${ }^{69}$ Simón, «Astudillo», doc. 17. Hay también una confirmación detallada del legado pontificio, cardenal Guillermo; Orejón, Astudillo, II, doc. 5. 
doña María heredades que produjeran 250 cargas de pan anuales, repartidas como sigue: 80 en la heredad de Astudillo, comprada a Mencía López; 30 en las aceñas de Astudillo, sobre el Pisuerga; 20 en otras aceñas viejas y en el molino de Junera, 80 en la heredad de Cubillas de Cerrato, 20 en la heredad de Cordovilla y otras 20 en la heredad de Villaverde-Mojina. Entregaba también 60 aranzadas de viñas en Astudillo, Cubillas, Cordovilla y Villaverde, que debían producir anualmente 1.200 cántaras de vino. Por último, concedía 12.000 maravedíes en rentas, situadas como sigue: 5.000 en el pecho de los moros de Burgos, 2.000 en Cubillas y otros 1.000 en la escribanía de Astudillo ${ }^{70}$. Se decía también que las monjas disponían de 40.000 maravedies para comprar heredades que podian rendir otros 4.000 maravedíes anuales. Con todo ello debía mantenerse la comunidad monástica, que según las disposiciones de la fundadora debía estar compuesta por 30 monjas, dos capellanes y ocho criados. Se conoce también el documento que recoge la entrega efectiva de algunos de estos bienes realizada por el mayordomo de doña María, Juan González de Pedrosa, probablemente a principios del año siguiente, $1357^{71}$.

Mediante la dotación de la fundadora obtuvo el convento un dominio de cierta importancia y un volumen considerable de rentas en dinero. El dominio fue ampliado en esos años y en los siguientes con donaciones de otros miembros de la familia de la fundadora ${ }^{72}$. Ya en 1355 doña Inés García, prima de Juan García de Padilla, dispuso al hacer testamento que se entregaran al convento de Santa Clara sus heredades en Pedrosa, Mahamud, Valbuena de Pisuerga y Cordovilla y que se volvieran a adquirir otras heredades en Matanza que había vendido a su sobrino y se entregaran también al convento, aunque dispuso que durante dos años con las rentas

${ }^{70}$ No coinciden las cantidades y desconocemos las razones, ni aun sumando los 1.384 maravedíes que calculaba la fundadora que debian sobrar cada año y recomendaba que se guardaran «porque todos los tiempos no son iguales ca los unos tiempos son muy buenos e muy frutuosos e los otros tiempos son muy contrarios e muy sin frutos e porque lo que remanece en los frutos de los buenos tiempos los buenos rregidores anlo de guardar para el fallecimiento de los frutos de los malos tiempos e desta guisa se mantene el mundo asta agora e se manterna fasta la fin del mundos; Simón, «Astudillo», doc. 17. El documento en conjunto resulta muy interesante porque se señalan detenidamente los gastos que preveía la fundadora y hay algún cálculo de los rendimientos de las heredades que cedia, aunque no podemos detenernos ahora más en el texto y ofrecer los detalles.

${ }^{71}$ El documento no lleva fecha, pero el mayordomo entregó los bienes a dos procuradoras del convento que fueron nombradas en septiembre de 1356; Simón, «Astudillo», docs. 33 y 34 .

72 Sobre el grupo familiar, las relaciones de parentesco, etc.; Simón, «Astudillo», pp. 134-137, y docs. 40 a 58; también Orejón, Astudillo, I, pp. 225-229, y II, p. 131. 
de esas heredades se atendiera a «mujeres menessterosas de mio linaje» ${ }^{73}$. $\mathrm{El}$ año siguiente recibió el convento una huerta en Astudillo procedente del testamento de Mayor Fernández, hija de Juan Fernández de Hinestrosa, $y$, por tanto, prima de doña María por línea materna ${ }^{74}$. Más importante fue la donación que hizo en 1359 la infanta doña Beatriz, hija de doña María y del rey Pedro I, al entregar al convento 3.000 maravedíes anuales sobre la martiniega de Astudillo ${ }^{75}$. Podemos incluir también en este bloque una donación realizada por Juan González de Pedrosa, personaje muy próximo a María de Padilla, ya que había sido su mayordomo entre 1355 y $1357^{76}$. En 1367 entregó al convento y a su hija Elvira González, monja en él, varias heredades en Astudillo, Torre y Valbuena de Pisuerga ${ }^{77}$.

No sabemos en qué empleó el convento los 40.000 maravedíes que le había entregado la fundadora para que comprara heredades. Únicamente conocemos dos compras de tierras en Astudillo, realizadas en 1353 y 1356, en las que el convento desembolsó 430 y 90 maravedíes respectivamente ${ }^{78}$. En todo caso, hay que considerar las heredades que se pudieron comprar con aquellos 40.000 maravedíes como parte de la dotación fundacional, y fuera de ello, las compras no tuvieron un papel relevante en la formación del dominio. Tampoco lo tuvieron los cambios, de los que sólo conocemos uno realizado en 1362 con el monasterio de San Miguel de Moral de la Reina, en el obispado de León, por el que ambos monasterios intercambiaron sus heredades respectivas en Astudillo y en Moral ${ }^{79}$.

${ }^{73}$ Simón, «Astudillo», doc. 29.

${ }^{74}$ Simón, «Astudillo», doc. 32.

${ }^{75}$ Simón, «Astudillo», doc. 20.

${ }^{76}$ Simón y Nieto le llama casi siempre Juan García de Pedrosa, probablemente por un desarrollo equivocado de la abreviación "G.» de su apellido. No conocemos relaciones de parentesco entre este personaje y los Padilla, pero es probable que las hubiera aunque en grado lejano. Es significativo que aunque Juan Fernández de Hinestrosa, tío de María de Padilla, esté perfectamente documentado como hijo de Fernán Gutiérrez de Hinestrosa, en alguna ocasión en el Becerro de las Bebetrias se le considere hijo de Juan Fernández de Pedrosa; véase Martínez Díez (1981), XI-2. A Juan González de Pedrosa se le menciona como mayordomo de doña María en Simón; «Astudillo», docs. 12, 28, 34 y 35. Su vinculación estrecha con doña María se constata también en 1356, cuando el legado pontificio le concede, aludiendo a su papel en la fundación del convento de Santa Clara, facultad para entrar en él siempre que fuera necesario para el convento; Orejón, Astudillo, II, doc. 11.

77 Orejón, Astudillo, doc. 15. Quizá haya que interpretar esta donación como la dote de su hija monja en el convento.

${ }^{78}$ Simón, «Astudillo», docs. 30 y 31.

${ }^{9}$ Desconozco cuándo pudo adquirir el convento de Santa Clara las heredades en Moral de la Reina; por su parte, las heredades que tenía el monasterio de San Miguel en Astudillo habían sido de la orden del Temple; Orejón, Astudillo, doc. 13. 
El dominio del convento de Santa Clara de Astudillo, como hemos ido viendo, se formó básicamente con los bienes entregados por doña María y en menor medida con bienes procedentes de otras donaciones hechas por miembros de su familia. A todo ello hay que añadir privilegios y participaciones en rentas regias otorgados por Pedro I y corroborados después por Enrique II. Estas rentas formaron el otro gran bloque de los bienes y derechos que se integraron en el dominio. Ya en 1355 Pedro I dio al convento una renta de 5.000 maravedíes anuales sobre el portazgo de Burgos, que si no alcanzara esa cantidad debía cubrirse con el pecho de los moros de la misma ciudad ${ }^{80}$. El año siguiente concedió al convento que pudiera tener 50 excusados para labrar sus fincas y cuidar su ganado, que podían tomarse en los lugares donados por María de Padilla en Astudillo y en la merindad de Castrojeriz ${ }^{81}$. En 1356 el rey dio también la mitad de la martiniega de Palencia, que suponía una renta de 3.300 maravedíes ${ }^{82}$. En 1359 Pedro I concedió al convento que pudiera tener 30 vasallos exentos en su puebla en torno al convento; esos vasallos estarían exentos del pago de tributos regios durante los diez próximos años y después pagarian los tributos, excepto la moneda forera, al convento ${ }^{83}$. Por último, aunque desconocemos la fecha en que fue concedido, Pedro I entregó otros 600 maravedíes al convento, situados en el pecho de los judíos de Astudillo ${ }^{84}$. Esa renta se unía a las otras que disfrutaba el convento en la villa y que habían recibido a través de María de Padilla - 1.000 maravedíes en la escribanía- y de doña Beatriz - 3.000 maravedíes en la martiniega-. En 1367 Enrique II cambió todas las rentas que poseía el convento en Astudillo por 8.000 maravedíes situados en las salinas de Castilla, al haber entregado dicha villa a su guarda mayor, Fernán Sánchez de Tobar ${ }^{85}$, y cambió también los 1.000 maravedíes del pecho de los moros de Burgos por otros tantos en el pecho de los judíos de Palencia ${ }^{86}$. Otro elemento a tener en cuenta, además de las rentas regias y del patrimonio territorial,

${ }^{80}$ En Simón, «Astudillo», doc. 15, se habla del pecho de los judíos de Burgos, y en Díaz Martín (1975), doc. 636, del de los moros. Sobre esta y otras donaciones regias, Orejón, Astudillo, I, pp. 214-220.

${ }^{81}$ Confirma además todas las donaciones que había hecho doña María y permite que las monjas puedan heredar de sus parientes y recibir donaciones; Orejón, Astudillo, II, doc. 4.

${ }^{82}$ Era la parte que el rey conservaba de esa renta; Díaz Martín (1975), doc. 713.

${ }^{83}$ Orejón, Astudillo, doc. 12.

${ }^{84}$ En 1363 el rey ordenó al concejo que efectuaran el pago correspondiente a ese año, pero la concesión era anterior; Díaz Martín (1975), doc. 838.

${ }^{85}$ Simón, «Astudillo», docs. 22 y 25 , y Orejón, Astudillo, I, pp. 62.

${ }^{86}$ Simón, «Astudillo», doc. 23, pp. 160; supongo que se trata de las rentas entregadas por Pedro I en 1355 o por María de Padilla en 1356. 
es el ganado. El convento de Santa Clara de Astudillo también dispuso de una cabaña ganadera, aunque las noticias sobre ella también son escasas. Pedro I le concedió privilegios de pastos por todo el reino para 40 bueyes, 3.000 ovejas y cabras y 200 cerdos $^{87}$.

\section{RECAPITULACIÓN}

Al reconstruir la historia de los dominios de muchas instituciones eclesiásticas los estudios trazan un panorama que se va haciendo más sombrio a medida que se avanza en la plena Edad Media; cuando se alcanzan las últimas décadas del siglo XIII y la primera mitad del siglo XIV muchos autores no dudan en hablar de crisis, crisis de muchos dominios eclesiásticos que vienen siendo uno de los elementos para interpretar la crisis global del siglo XIV. El punto culminante de la crisis de esos dominios eclesiásticos sería el conocido episodio de las encomiendas de 1380. Esas líneas generales de evolución son aceptadas por muchos de los autores que se han ocupado del tema y derivan de los estudios de dominios de instituciones de órdenes monásticas fundadas en su mayoría entre los siglos $\mathrm{x}$ y XII. Hasta ahora se ha prestado bastante menos atención a la formación y evolución de los dominios de instituciones pertenecientes a las nuevas órdenes que se extendieron a partir del siglo XIII. Sin embargo, si se considera la evolución de las bases materiales del poder de la Iglesia en su conjunto, es necesario reconocer que los patrimonios eclesiásticos no cesaron de crecer durante toda la Edad Media, sin solución de continuidad. Las órdenes nuevas dieron un importante impulso a ese crecimiento a partir del siglo XIII. En mi opinión, esta perspectiva es especialmente importante al trazar la historia de una región o de un territorio determinado. De la misma manera, es importante reconocer las características específicas de los nuevos dominios que fueron surgiendo, la manera en que las instituciones conventuales desarrollaron sus formas de dominación social y económica, acomodándose a la evolución general del sistema feudal. Cada uno de los tres dominios que he analizado brevemente en este artículo tiene sus propias características, derivadas, en buena medida, de las circunstancias concretas de su fundación. Sin embargo, la visión conjunta de los tres permite destacar algunos rasgos generales.

${ }^{87}$ Se conoce la noticia a través de una confirmación del legado pontificio en 1356; Orejón, Astudillo, doc. 6. 
1. Los dominios rurales de estas instituciones estuvieron formados, mayoritariamente, por tierras en lugares sometidos al señorío de otros nobles o instituciones eclesiásticas. En sus dominios, los mendicantes de Castilla la Vieja no integraron, generalmente, derechos de ejercicio de señorío sobre aldeas completas o partes de aldeas, sino derechos de propiedad en tierras trabajadas por campesinos sometidos al señorío de otros señores ${ }^{38}$. Los mendicantes no fueron señores, sino propietarios. Es muy probable que el convento de la Trinidad no pudiera ejercer derechos de señorío en ninguno de los aproximadamente 50 lugares en los que tenía tierras. El convento de Caleruega tenía tierras en otros 35 lugares aproximadamente, pero sólo disponía de derechos señoriales en dos de ellos; uno era la propia villa de Caleruega y otro la villa de Espinosa de Cervera, lugar bajo el señorío de un total de cinco señores: el convento de Caleruega, el monasterio de Silos, el monasterio de Renuncio y los nobles Tello Álvarez de Quintanilla de los Caballeros y Juan Díaz de Rocaful ${ }^{89}$. El convento de Santa Clara de Astudillo tuvo heredades en al menos nueve lugares. Sus derechos señoriales se concretaban en el lugar de Cubillas de Cerrato, incluido en la primera dotación de María de Padilla en 1355, y en los vasallos de su puebla de Astudillo ${ }^{90}$. El convento vendió Cubillas a Inés de Guzmán en 1454 a cambio de una renta anual de 30.000 maravedíes de juro de heredad, y en relación a sus vasallos exentos de Astudillo tuvo frecuentes problemas con el concejo y con los sucesivos señores de la villa de la familia Tobar $^{91}$.

La razón que explica la escasa presencia de derechos de ejercicio de señorío puede estar en el alto grado de señorialización de la zona, ya antes

${ }^{88}$ Puede constatarse mediante una revisión rápida del Becerro de las Bebetrías. La excepción a esta idea general sería el convento de Santa Clara de Medina de Pomar, fundado en 1313 por Sancho Sánchez de Velasco; véase Gonzalez Crespo (1981) y algunos textos relativos al dominio de este convento - la dotación inicial y otras donaciones importantes posteriores- en García y Sáinz de Baranda (1989), pp. 394 y ss. A mediados del siglo XIV el convento de Medina disfrutaba de derechos señoriales sobre cuatro lugares: Cubillos del Rojo, en la merindad de Aguilar, donde tenía cinco vasallos, y Villamezán, Santa Olalla de Valdivielso y Gayangos, en la merindad de Castilla Vieja, donde tanía uno, tres y un vasallo, respectivamente; en todos los casos el convento compartía los derechos de señorío con otros señores y siempre con miembros del grupo familiar de los Velasco, sucesores de Sancho Sánchez; además el Becerro dice que el convento tenia también un solar en Mozares, también en la merindad de Castilla Vieja, pero en 1352 estaba yermo. Véase Martínez Díez (1981), VII-109 y XIV-84, 201, 220 y 244, respectivamente.

${ }^{89}$ Martínez Díez (1981), XV-20.

90 Simón, «Astudillo», doc. 16, y Orejón, Astudillo, doc. 12.

91 Orejón, Astudillo, I, pp. 230-236 y 240-242. 
de que los mendicantes comenzaran a formar sus dominios. Un buen ejemplo es la compleja, y seguramente costosa, operación que llevó a cabo el rey Alfonso $X$ para poder entregar al convento de Caleruega la villa del mismo nombre. Por otro lado, los fundadores y benefactores de los conventos generalmente prefirieron concederles propiedades y rentas y seguir reservándose para sí mismos y sus familias los derechos de señorío. Así, María de Padilla, en efecto, entregó a su convento de Santa Clara el lugar de Cubillas de Cerrato y le entregó también otras heredades que habían sido de su padre, pero de esos otros lugares exceptuó las casas fuertes y los vasallos, dando sólo la beredad llana ${ }^{92}$. Los textos que se han conservado ofrecen muy pocos datos sobre las formas de explotación de las heredades que desarrollaron los conventuales, la política de arrendamiento, los plazos, etc., de manera que no es posible determinar las similitudes o diferencias respecto a lo conocido para otras instituciones monásticas en esa época.

2. En mi opinión, el elemento más característico en la estructura de los ingresos de los conventos es la importancia de los situados en las rentas regias. Éste es un elemento claro en los conventos de Caleruega y Astudillo, aunque no está presente en el de la Trinidad de Burgos. Este último, como ya he indicado, desarrolló su dominio al margen de apoyo regio y también fue el que dispuso - usando como indicador sólo el número de villas donde tenía heredades - de un mayor patrimonio rural. Por otro lado, el convento de la Trinidad fue fundado a principios del siglo XIII, cuando la fiscalidad regia, de la que se beneficiaron abundantemente otros conventos, apenas comenzaba a desarrollarse. La diferente proporción entre derechos de señorío y derechos de propiedad -con las matizaciones que he indicado- y la importancia de los situados en las rentas regias marcan las características de los dominios de las nuevas órdenes y los diferencian de los de las órdenes monásticas de fundación anterior.

El siglo XIII y la primera mitad del siglo XTV representan un momento específico en la evolución de la fiscalidad regia en Castilla. Es el momento de desarrollo de rentas como las martiniegas, de origen anterior pero que ahora vemos desarrollarse con claridad - cquizá por las características de la documentación? - Lo mismo puede decirse de los portazgos, los pechos de moros y judíos, las rentas de salinas y, desde las últimas décadas del siglo XIII, las escribanías. Son algunas de las rentas que en este momento

\footnotetext{
${ }^{42}$ Simón, «Astudillo», doc. 16.
} 
forman una parte importante de la fiscalidad regia y que desde las últimas décadas del siglo XII comienzan a ser parcialmente cedidas a algunos señores. Mientras tanto, los reyes se reservan casi siempre las monedas y servicios, que se desarrollan también a lo largo del siglo xil y que, junto a tercias y alcabalas, formarán el eje de la fiscalidad regia bajomedieval ${ }^{93}$. Durante la baja Edad Media la estructura de los ingresos señoriales estará cada vez más determinada por los situados en las rentas regias, entonces especialmente las alcabalas ${ }^{94}$. El desarrollo de la renta feudal centralizada supone un cambio sustancial en la forma como los señores, nobles y eclesiásticos, ejercían su poder. Sin embargo, como muestran los ejemplos de los conventos de Caleruega y Astudillo, los orígenes del fenómeno para algunos señores se sitúan ya en las últimas décadas del siglo XIU. El monasterio de Caleruega dispuso de una renta de unos 8.000 maravedíes desde finales del siglo XIII, que estuvo situada en martiniegas, rentas de salinas, portazgos, pechos de judíos y nuevamente en rentas de salinas. Mejor dotado estuvo en este sentido el convento de Astudillo, que llegó a acumular rentas por un valor total cercano a los 25.000 maravedíes en portazgos, pechos de moros y judios, escribanías y martiniegas.

Para valorar lo que significan estas rentas puede compararse con la estimación de los ingresos efectivos de algunos monasterios benedictinos en 1338 realizada por S. Moreta a partir del Libro de Cuentas de los Monasterios Benedictinos de la Provincia de Toledo. Según este autor, los ingresos efectivos, las rentas salvas, del monasterio de Silos en esa fecha eran de $39.828,5$ maravedíes y el monasterio tenía propiedades en unos 87 lugares; el monasterio de Cardeña ingresaba 27.942 maravedíes a partir de sus propiedades y derechos en unos 81 lugares; el monasterio de San Zoilo de Carrión ingresaba 19.078,5 maravedies con unos 52 lugares; el monasterio de Arlanza obtenía 9.130,7 maravedíes a partir de sus 77 lugares, etc. ${ }^{95}$.

No es posible calcular, a partir de los datos disponibles, qué porcentaje de ingresos suponía la participación en las rentas regias respecto al total de ingresos de estos conventos. Pero el documento de dotación del convento de Santa Clara por María de Padilla, de 1356, permite alguna com-

\footnotetext{
${ }^{43}$ Ladero Quesada (1982) y (1993).

94 Entre otros, puede verse Martínez Moro (1977), Martinez Sopena (1977), Quinatanilla Raso (1982), Yun Casalilla (1987) y Casado Alonso (1987).

${ }^{45}$ Moreta Velayos (1974), Cuadro 4.3, p. 118. También García González (1972), donde edita el texto del Libro de Cuentas de 1338 en pp. 128 y ss.
} 
paración interesante. La fundadora declara que entregaba heredades en diversos lugares que podian rendir en total 250 cargas de cereal, mitad trigo y mitad cebada, y 1.200 cántaras de vino. Podemos calcular el valor de esas rentas en especie con el precio del trigo, la cebada y el vino en Burgos y en Carrión en 1338. Si el convento hubiera vendido esos productos en Burgos en 1338 hubiera obtenido algo más de 7.000 maravedies -algo más de 3.000 maravedíes por el cereal y casi 4.000 por el vino-. Pero el mercado de Burgos estaba entre los más caros de la zona; vendiendo esos productos en Carrión, por ejemplo, el convento hubiera obtenido en 1338 sólo unos 3.000 maravedíes - unos 1.900 por el cereal y unos 1.200 por el vino- ${ }^{96}$. Los precios en los años cincuenta eran bastante más altos que en los años treinta; para los cincuenta sólo dispongo de datos fiables sobre el precio del cereal en el mercado de Burgos relativos a 1352; entonces una carga de trigo en Burgos valía entre 28 y 32 maravedíes y una carga de cebada, entre 18 y 20 maravedíes, aproximadamente el doble que en 1338, lo que hubiera permitido obtener al convento, por sus 250 cargas de cereal, entre unos 5.700 y 6.500 maravedíes ${ }^{97}$. Los datos presentados no pretenden en absoluto ser concluyentes, sino sólo aproximados. Pero creo que son suficientes para indicar la importancia de la participación en las rentas regias dentro de las economías de los conventos de Caleruega y Astudillo ${ }^{98}$. En este aspecto, estos conventos son precursores de lo que después se generalizará, si no al conjunto de los señores, sí a sectores muy importantes de la clase señorial.

3. He indicado en las páginas anteriores que el número de monjas de los conventos de Caleruega y Astudillo eran expresivos no sólo del éxito religioso de las nuevas órdenes, sino también del éxito económico de las fundaciones. Caleruega albergaba más de sesenta monjas hacia 1330

\% Hago estos cálculos a partir de los datos de precios que ofrece Moreta Velayos (1974), Cuadros 4.1 y 4.2, pp. 113-115. Los datos que atribuyo a Burgos son los que aportan las cuentas del monasterio de San Juan de la ciudad; según esos datos, una fanega de trigo costaba cuatro maravedies y una fanega de cebada 2,5 maravedíes; en Carrión los datos proceden del monasterio de San Zoilo y allí una carga de trigo valía 10 maravedíes y una carga de cebada cinco maravedíes (recuérdese que una carga tenía cuatro fanegas).

${ }_{77}$ Los precios los aporta Valdeón (1970), p. 327.

${ }^{98} \mathrm{La}$ conclusión es más contundente aún en el caso del convento de San Pablo de Peñafiel, convento que en la dotación de 1320 recibió rentas por valor de 8.500 maravedíes, 5.000 de los cuales correspondían a parte de la martiniega de Peñafiel, rentas que aumentaron después; véase García García (1986), aunque en este caso la autora considera rentas señoriales a la martiniega, el portazgo, el pecho de los judios, etc., que disfrutaba el convento al haberle sido dadas por el señor de la villa, don Juan Manuel, cuyo padre el infante don Manuel había obtenido la villa - y las rentas regias-en 1283; ibid., pp. 11 y 12. 
y era necesario reducir el número. En el convento de Astudillo la fundadora preveía que hubiera 30 monjas, dos frailes y ocho servidores. El monasterio femenino más poderoso de Castilla, el de Santa María de Las Huelgas, de Burgos, debía contar con unas 150 monjas, según se habia dispuesto a mediados del siglo XIII ${ }^{99}$. Las dotes que entregaban las monjas al ingresar en la comunidad tuvieron que ser otra fuente de ingresos relevante para los conventos, pero apenas se conocen.

Algunos textos conservados que recogen donaciones de tierras mencionan la circunstancia de la entrada en la orden, pero son pocos documentos. Los textos que indican el pago de dotes en el monasterio de Caleruega son sólo dos, en 1293 y 1351; mediante ambos obtuvo el convento heredades en Baños de Valdearados ${ }^{100}$. En cuanto al convento de Astudillo, sólo uno de los textos conservados refleja claramente el pago de una dote ${ }^{101}$. Otros documentos pueden encubrir realidades similares, pero en todo caso son susceptibles de varias interpretaciones. Así, entregas de heredades a cambio de mantenimiento vitalicio por parte del convento ${ }^{102}$, o donaciones hechas a los conventos por monjas que ya han ingresado en las órdenes respectivas ${ }^{103}$. Sea como fuere, aun en la interpretación más favorable, contamos con muy pocos textos que podamos relacionar con las dotes. Por otra parte, los textos conservados no permiten una valoración económica de los bienes entregados; las donantes entregan heredades en uno u otro lugar, pero ¿qué tipo de heredades, de qué extensión?

La escasez de datos documentales sobre las dotes de las monjas en este período merece una reflexión. Si las dotes se hubieran reflejado en documentos, los conventos habrían tenido que conservarlos; si hoy no se conoce es o bien porque no llegaron a realizarse o bien porque se han perdido por razones fortuitas. También debemos tener en cuenta que tanto el convento de Caleruega como el de Astudillo tuvieron heredades cuya forma de adquisición desconocemos. Ya lo he mencionado, y al menos como posibilidad, hay que considerar que algunas de esas heredades pudieron llegar a manos de los conventos mediante dotes desconocidas para nosotros. Sin embargo, aunque eso es posible, me inclino a pensar que

99 Lizoain Garrido y García González (1988), pp. 366-377.

${ }^{10 *}$ Caleruega, docs. CCLXVI y CCLXXXVII.

101 Orejón, Astudillo, doc. 15.

102 Caleruega, doc. CCLXXV.

${ }^{103}$ Simón, «Astudillo», docs. 37, 38 y 39. Para otros monasterios cistercienses femeninos véase Lizoain Garrido y García González (1988), pp. 106-107, y Pérez-Embid (1986). 
la mayor parte de las dotes de las monjas correspondieron a entregas en metálico ${ }^{104}$ que no quedaron reflejadas en ningún documento conservado. Lamentablemente es imposible saberlo con certeza y valorar qué supusieron para las economías conventuales. Pero hay una relación que sí puede establecerse. La estructura de los dominios conventuales les permitía una situación económica acomodada - la vida en los claustros conventuales debía ser más agradable en esos años que la de muchos claustros benedictinos, por ejemplo-, lo que se traducía en una mayor afluencia de monjas que, a su vez, significaba mayores ingresos por la vía de las dotes.

El prestigio religioso de estas instituciones se reflejaba también en la elección como lugar de enterramiento. A cambio de los enterramientos los conventos y otras instituciones eclesiásticas obtuvieron bienes diversos. Es un asunto bien conocido que se refleja en muchas de las monografías sobre dominios eclesiásticos, casi siempre al estudiar los motivos de las donaciones. En los casos que analizo aquí la documentación de Caleruega recoge algunos ejemplos de donaciones de tierras a cambio de enterramientos ${ }^{105}$. Los documentos conservados también recogen algunos ejemplos en el convento de la Trinidad de Burgos, a pesar de las restricciones impuestas por las autoridades diocesanas. Podemos preguntarnos si, como probablemente sucedía con las dotes, es posible que hubiera otras concesiones de enterramientos no a cambio de tierras, sino también a cambio de cantidades en metálico; concesiones o acuerdos que no quedaron reflejadas en textos, o no al menos en los que se han conservado. Por ese camino algunos conventos pudieron obtener ingresos importantes.

Otra fuente de ingresos en metálico difícilmente cuantificables son las dotaciones testamentarias para misas, capellanías, etc. ${ }^{106}$. Las instituciones procuraban conservar copias de los testamentos de los que obtenían beneficios económicos, sobre todo de aquellos que les proporcionaban mayores ingresos. Pero es necesario considerar que en este aspecto, como en los señalados más arriba, la escasa documentación conservada puede reflejar sólo una pequeña parte de la realidad. El convento de la Trinidad parece haber recibido con cierta frecuencia donaciones testamentarias. Su acti-

${ }^{104}$ Posteriormente las dotes constaban fundamentalmente de cantidades en metálico, rentas y bienes muebles; ejemplos relativos a conventos andaluces en el siglo XVI en Espinar Moreno, García Romera y Porti Durán (1989). Debo esta referencia a I. Beceiro.

${ }^{105}$ Caleruega, docs. CCLXXIV y CCXCIV, de 1322 y 1381, respectivamente.

${ }_{10}$ The Textos relativos a donaciones testamentarias en Trinidad, docs. 98, 101, 129, 145 , 186 y 193, y Caleruega, docs. CCLXXIV y CCXCIV. 
vidad específica relacionada con la redención de cautivos cristianos en manos musulmanas le confería un valor singular en la religiosidad medieval. Para esa actividad obtenía limosnas en metálico cuya cuantía, distribución del gasto, etc., también resulta desconocida.

4. Tampoco es posible valorar económicamente otra fuente de ingresos como era la cabaña ganadera. La propiedad de rebaños queda reflejada en los privilegios de pastos que concedieron los reyes, pero no deja de ser un reflejo indirecto. Según he indicado, el convento de Astudillo obtuvo privilegios de pastos para 3.000 ovejas y cabras, 200 cerdos y 40 bueyes; el número de cabezas exentas del convento de Caleruega varía en los distintos privilegios, pero las cifras más elevas - y las que más se repitenhablan de 10.000 ovejas, 500 cabras, 1.000 vacas, 1.000 cerdos y 200 yeguas. Son cifras comparables e incluso superiores a las de muchas otras instituciones eclesiásticas de la zona ${ }^{107}$.

La participación de la ganadería en los ingresos señoriales en Castilla en la Edad Media es mal conocida en general. La formación de los grandes rebaños de los monasterios sí ha sido estudiada a partir de privilegios regios similares a los que he mencionado para estos conventos, pero faltan conclusiones sobre su impacto económico ${ }^{108}$. Un primer problema consiste en determinar si tanto estos conventos como las otras instituciones que recibieron privilegios similares dispusieron realmente de rebaños de esa entidad. En segundo lugar sería necesario conocer qué ingresos obtenían a partir de las cabañas ganaderas. Resulta muy significativo que un registro como el Libro de Cuentas de 1338 de los monasterios benedictinos no incluya en ningún caso los ingresos procedentes de las cabañas ganaderas de los respectivos centros. ¿Por qué? ¿Había desaparecido, por ejemplo, la importante cabaña del monasterio de Oña en 1338 a causa de las guerras que se desarrollaron hasta los años veinte? Los estudios de diversos dominios

${ }^{107}$ El monasterio de Cardeña obtuvo privilegios de pastos para 6.000 ovejas y cabras y 50 yeguas; el monasterio de Oña, para 15.000 cabezas entre ovejas, cabras y yeguas; el monasterio de San Millán, para 10.000 ovejas y cabras y 100 yeguas; el monasterio de La Vid, para 4.000 ovejas y cabras, 100 yeguas y 200 cerdos; el monasterio de Párraces, para 3.000 ovejas, 1.500 vacas, 800 cerdos y 500 yeguas; el monasterio de Las Huelgas, de Burgos, para 9.000 ovejas, 150 yeguas y 3.000 cerdos. La mayor cabaña ovina, con diferencia, sería la del Hospital del Rey, de Burgos, que obtuvo privilegios de pastos para 30.000 ovejas, 200 cabras y 100 yeguas. Expongo los datos que ofrecen Martínez García (1986), pp. 226-227, y Peña Pérez (1991) p. 228, n. 364. Véase también Pastor (1980), pp. 152-154.

${ }^{108}$ Pastor (1980). Una visión general reciente, donde puede encontrarse la bibliografía de referencia en Peña Pérez (1994), pp. 430-437. 
eclesiásticos reflejan en el mejor de los casos la existencia de los rebaños, pero no arrojan suficiente luz sobre su trascendencia económica para las instituciones.

\section{BIBLIOGRAFIA}

ÁLVAREZ Borge, I. (1993): «Los concejos contra sus señores. Luchas antiseñoriales en villas de abadengo en Castilla durante el siglo XIv», en Historia Social, núm. 15, pp. 3-27.

- (1996): Poder y relaciones sociales en Castilla en la Edad Media. Los territorios entre el Arlanzón y el Duero en los siglos X al XIN, Valladolid, Junta de Castilla y León.

- (1996): «Los señoríos en Castilla la Vieja a mediados del siglo XIV», en Studia Histórica. Historia Medieval, núm. 14, pp. 181-220.

Aniz Iriarte, C., y Diaz Martin, L. V. (coords.) (1994): Santo Domingo de Caleruega. Jornadas de Estudios Medievales (1992-1993), Salamanca, San Esteban.

- (1995): Santo Domingo de Caleruega. Contexto cultural, Salamanca, San Esteban.

- (1996): Santo Domingo de Caleruega. Contexto eclesial religioso, Salamanca, San Esteban.

Ávila y Diaz de Ubierna, G. (1961 y 1962): «El antiguo convento de la Santísima Trinidad y el Santísimo Cristo de Burgos o de las Santas Gotas que se venera en la iglesia parroquial de San Gil», en Boletín de la Institución Fernán González, varios números.

CASAdO AlONSO, H. (1985): «La propiedad rural de la oligarquía burgalesa en el siglo XV», en La ciudad bispánica durante los siglos XIII al XVI, t. I, Madrid, Universidad Complutense, pp. 581-596.

- (1987): Señores, mercaderes y campesinos. La comarca de Burgos a fines de la Edad Media, Valladolid, Junta de Castilla y León.

Dízz Martin, L. V. (1975): Itinerario y regesta de Pedro I, Valladolid, Universidad de Valladolid.

- (1995): Reyes de Castilla y León. Pedro I, 1350-1369, Burgos, Diputación Provincial de Palencia.

Espinar Moreno, M.; Garcia Romera, M. V., y Porti Duran, N. (1989): «Dotes de religiosas en las tierras de Baza y Guadix», en A. MuNOz FerNÁNDEZ (ed.), Las mujeres en el cristianismo medieval. Imágenes teóricas y cauces de actuación religiosa, Madrid, Asociación Cultural Al-Mudayna.

EstepA DiEZ, C. (1994): «Estructuras de poder en Castilla (siglos xal-xiII). El poder señorial en las merindades "burgalesas"», en Burgos en la Plena Edad Media, Burgos, pp. 245.294, Asociación Provincial de Libreros de Burgos.

Estow, C. (1995): Pedro the Cruel of Castile, 1350-1369, Leiden.

García Aragón, L. (1985): Documentación del monasterio de la Trinidad de Burgos (1198-1400), Burgos, J. M. Garrido.

García Garcí, E. (1986): San Juan y San Pablo de Peñafiel. Economía y Sociedad de un convento dominico castellano (1318-1512), Valladolid, Junta de Castilla y León. 
GaRCía GonzÁlez, J. J. (1972): Vida económica de los monasterio benedictinos en el siglo XIV, Valladolid, Universidad de Valladolid.

García Oro, J. (1988): Francisco de Asís en la España medieval, Santiago de Compostela, Liceo Franciscano.

Garcí Toraño, P. (1996): El rey don Pedro el Cruel y su mundo, Madrid, Marcial Pons.

García Turza, F. J. (1996): «De los monjes a los frailes: la coyuntura del año 1200 en la sociedad y en la Iglesia», en VI Semana de Estudios Medievales de Nájera, 1995, Logroño, Instituto de Estudios Riojanos, pp. 13-28.

García VillosladA, R. (dir.) (1982): Historia de la Iglesia en España, Madrid, Editorial Católica.

García y SáInz de Baranda, J. (1989): Apuntes bistóricos de la ciudad de Medina de Pomar, Burgos, Centro de Iniciativas Turisticas.

Ginarte González, V. (1979): La Orden Trinitaria. Compendio bistórico de los Descalzos Trinitarios, Salamanca, Ed. PP. Trinitarios.

GonzÁlez CREsPo, E. (1981): Elevación de un linaje nobiliario castellano en la Baja Edad Media: los Velasco, Madrid, Universidad Complutense.

González González, C. (1993): Real Monasterio de santo Domingo de Caleruega. Fundación de Alfonso X el Sabio, Salamanca, San Esteban.

LADERo QuesADA, M. A. (1982): «Las transformaciones de la fiscalidad regia castellano-leonesa en la segunda mitad del siglo Xmi (1252-1312)», en Historia de la Hacienda española (épocas antigua y medieval). Homenaje al Profesor García de Valdeavellano, Madrid, Instituto de Estudios Fiscales, pp. 319-406.

- (1993): Fiscalidad y poder real en Castilla (1252-1369), Madrid, Universidad Complutense.

Linage Conde, A. (1983): «De los monjes a los frailes. Notas sobre la implantación de la vida religiosa medieval en el territorio castellano-leonés», en $E l$ pasado bistórico de Castilla y León. I Congreso de Historia de Castilla y León, vol. 1 (Edad Media), Valladolid, Junta de Castilla y León, pp. 263-274.

LizoAin Garrido, J. M., y García González, J. J. (1988): El monasterio de Las Huelgas. Historia de un monasterio cisterciense burgalés (siglos XII y XIII), Burgos, J. M. Garrido.

Martín Martín, J. L. (1997): «Propiedad y tenencia de la tierra en la Extremadura leonesa medieval: las órdenes mendicantes», en VIII Congreso de Historia Agraria, Salamanca, Seminario de Historia Agraria, pp. 311-320.

Martínez Diez, G. (1981): Libro Becerro de las Bebetrías. Estudio y texto critico, León, Centro de Estudios San Isidoro.

Martínez Garcia, L. (1986): El bospital del Rey de Burgos. Un señorio medieval en la expansión y en la crisis (siglos XIII y XIV), Burgos, J. M. Garrido.

Martínez Liébana, E. (1931): Colección Diplomática del Real Convento de Santo Domingo de Caleruega, Vergara, Ed. Santísimo Rosario.

Martinez Moro, J. (1977): La renta feudal en la Castilla del siglo xV. Consideraciones metodológicas y otras, Valladolid, Universidad de Valladolid.

Martinez Sopena, P. (1977): El estado señorial de Medina de Rioseco bajo el almirante Alfonso Enriquez (1389-1430), Valladolid, Universidad de Valladolid.

Menéndez Pidal, R. (1966): Documentos Lingüísticos de España. I. Reino de Castilla, Madrid, CSIC. 
Moreta Velayos, S. (1974): Rentas monásticas en Castilla: problemas de método, Salamanca, Universidad de Salamanca.

Moxo, S. de (1973): «El patrimonio dominical de un consejero de Alfonso XI. Los señorios de Fernán Sánchez de Valladolid», en Revista de la Universidad Complutense, núm. 85, Homenaje a Gómez Moreno, II, pp. 126-162.

Orejón Calvo, A. (1917): Historia del convento de Santa Clara de Astudillo, Palencia, Imprenta Casa de Expósitos y Hospicio.

- (1983 y 1984): Historia de Astudillo y del convento de Santa Clara, Palencia, Diputación Provincial de Palencia.

Palacios Martin, B. (1996): «Los dominicos y las órdenes mendicantes en el siglo XIII», en VI Semana de Estudios Medievales de Nájera, 1995, Logroño, Instituto de Estudios Riojanos, pp. 29-41.

PASTOR, R. (1980): «La lana en Castilla y León antes de la organización de la Mesta», en Conflictos sociales y estancamiento económico en la España medieval, Barcelona, Ariel, pp. 133-171.

Peña Pérez, F. J. (1991): El monasterio de San Juan de Burgos. Dinámica de un modelo cultural feudal, Burgos, J. M. Garrido.

- (1993): «Expansión de las órdenes conventuales en León y Castilla: franciscanos y dominicos en el siglo XII», en III Semana de Estudios Medievales de Nájera, 1992, Logroño, Instituto de Estudios Riojanos, pp. 179-198.

- (1994): «La economía burgalesa en la Plena Edad Media», en Burgos en la Plena Edad Media, Burgos, Asociación Provincial de Libreros de Burgos, pp. 411-458.

Pérez-Embid, J. (1986): «El cister femenino en Castilla y León. La formación de los dominios (siglos XII-XII)», en En la España Medieval. V. Estudios en memoria del Profesor D. Claudio Sáncbez Albomoz, t. II, Madrid, pp. 761-796. Quintanilla Raso, C. (1982): «Haciendas señoriales nobiliarias en el reino de Castilla a fines de la Edad Media», en Historia de la Hacienda española (épocas antigua y medieval). Homenaje al Profesor Garcia de Valdeavellano, Madrid, Instituto de Estudios Fiscales, 1982.

Rodriguez NúNEZ, C. (1996): «El conventualismo femenino: las Clarisas», en VI Semana de Estudios Medievales de Nájera, 1995, Logroño, Instituto de Estudios Riojanos, pp. 87-99.

Rucquol, A. (1996): «Los franciscanos en el Reino de Castilla», en VI Semana de Estudios Medievales de Nájera, 1995, Logroño, Instituto de Estudios Riojanos, pp. 65-86.

Ruız, F. T. (1981): Sociedad y poder real en Castilla, Barcelona, Ariel.

SAENZ DE HARO, T. (1996): «Franciscanismo y espiritualidad. Bibliografía», en VI Semana de Estudios Medievales de Nájera, 1995, Logroño, Instituto de Estudios Riojanos, pp. 301-336.

Serrano, L. (1922): Don Mauricio, Obispo de Burgos y fundador de su Catedral, Madrid, Imprenta Blass.

Simón y NIETO, F. (1896): «El monasterio de Santa Clara de Astudillo. Índice de su archivo. Nuevas noticias de María de Padilla», en Boletin de la Real Academia de la Historia, XXIX, pp. 118-178. 
VALDEÓN, J. (1970): «Datos para la historia social y económica de la Castilla medieval: las rentas de la Catedral de Burgos de 1352», en Anuario de Historia Económica y Social, núm. 3, pp. 325-338.

V.AA. (1994): Las Clarisas en España y Portugal. Congreso Internacional, Madrid, Asociación Hispánica de Estudios Franciscanos.

Yun CASALILLA, B. (1987): Sobre la transición del feudalismo al capitalismo en Castilla. Economia y sociedad en Tierra de Campos (1500-1830), Valladolid, Junta de Castilla y León. 